\title{
Aircraft measurements of water vapor heavy isotope ratios in the marine boundary layer and lower troposphere during ORACLES
}

\author{
Dean Henze ${ }^{1}$, David Noone ${ }^{1,2}$, Darin Toohey ${ }^{3}$ \\ ${ }^{1}$ College of Earth, Ocean, and Atmospheric Science, Oregon State University, OR, USA \\ ${ }^{2}$ Department of Physics, University of Auckland, Auckland, New Zealand \\ ${ }^{3}$ Department of Atmospheric and Ocean Sciences University of Colorado, CO, USA
}

5

Correspondence to: Dean Henze (henzede@oregonstate.edu), David Noone (david.noone@auckland.ac.nz)

\begin{abstract}
This paper presents the water vapor heavy isotope ratio measurement system developed for aircraft in-situ measurements and used in the NASA ObseRvations of Aerosols above CLouds and their intEractionS (ORACLES) project. The resultant dataset collected, which includes measurements of specific humidity and the heavy isotope ratios $\mathrm{D} / \mathrm{H}$ and ${ }^{18} \mathrm{O} /{ }^{16} \mathrm{O}$, is also presented. Aircraft sampling took place in the southeast Atlantic marine boundary layer and lower troposphere (equator to $22^{\circ} \mathrm{S}$ ) over the months of Sept. 2016, Aug. 2017, and Oct. 2018. Isotope measurements were made using cavity ring-down spectroscopic analyzers integrated into the Water Isotope System for Precipitation and Entrainment Research (WISPER). The water concentration and isotopic data accompanied a suite of other variables including standard meteorological quantities (wind, temperature, moisture), trace gas and aerosol concentrations, radar, and lidar remote sensing. From an isotope perspective, the $300+$ hours of $1 \mathrm{~Hz}$ in-situ data at levels in the atmosphere ranging from $70 \mathrm{~m}$ to $6 \mathrm{~km}$ represents a remarkably large and vertically resolved dataset. This paper provides a brief overview of the ORACLES mission and describes how water vapor heavy isotope ratios fit within the experimental design. Overviews of the sampling region and WISPER system setup are presented, along with calibration details, measurement uncertainties, and suggested data usage. Characteristics in the spatial variability of the study region over the three sampling periods are highlighted with latitude-altitude curtains. A number of individual tropospheric profiles are presented to illustrate the fidelity with which a series of different hydrologic processes are captured by the observations. The curtains and profiles demonstrate the dataset's potential to provide a comprehensive perspective on moisture transport and isotopic content in this region. Readers interested in a quick reference to data usage and uncertainty estimation can consult the beginning of section 5. Data for the

30 Sept. 2016, Aug. 2017, and Oct. 2018 sampling periods can be accessed at https://doi.org/10.5067/Suborbital/ORACLES/P3/2016_V2, https://doi.org/10.5067/Suborbital/ORACLES/P3/2017_V2, and https://doi.org/10.5067/Suborbital/ORACLES/P3/2018_V2, respectively (see references for ORACLES Science Team, 2020 - 2016 P3 data, 2017 P3 data, and 2018 P3 data).
\end{abstract}

\section{Introduction}

Uncertainties in general circulation model (GCM) representations of marine boundary layer (MBL) low cloud cover contribute substantially to the spread in model predictions of future climate (Bony \& Dufresne, 2005). Further uncertainties in GCM output arise from an incomplete understanding of cloud-aerosol interactions. For example, the Fifth Assessment Report from the Intergovernmental Panel on Climate Change (IPCC) identified cloud-aerosol interactions as the largest contribution to uncertainty in total radiative forcing estimates (Boucher et al., 2013 IPCC report, Chapter 7). Given these limitations, there is a need to develop a refined understanding of several key processes that control MBL low cloud cover.

The formation of marine low clouds is linked in part to the energy and moisture budgets of the marine boundary

45 layer (Wood 2012; Vial et al., 2017), and there is a need for tighter observational constraints on these budgets. Measurements of the oxygen and hydrogen stable isotopic composition of atmospheric water vapor present a way to obtain tighter constraints since they provide information on the relative importance of air mass mixing, precipitation, 
and other moisture transport processes not easy to determine using conventional thermodynamic variables alone (e.g. Risi et al., 2008; Brown et al., 2013; Galewsky et al., 2016). Therefore, water vapor isotope ratios can be utilized to constrain uncertainties in low cloud thermodynamics. Potentially, they could be applied to moisture transport and cloud microphysics processes associated with aerosol indirect effects, such as the lifetime effect and precipitation suppression. To date, detailed vertical profiles in the lower troposphere are sparse (e.g. Ehhalt, 1974; Herman et al., 2014; Dyroff et al., 2015). This limits the degree to which isotope ratios can be fully leveraged to provide a comprehensive depiction of the atmospheric water budget in the lower troposphere.

55 The NASA ObseRvations of Aerosols above CLouds and their intEractionS (ORACLES) mission provides an extensive data set of aircraft in-situ aerosol, cloud microphysical, water vapor heavy isotope ratio, and meteorological measurements in the southeast Atlantic (Fig. 1) during the months of Sept. 2016, Aug. 2017, and Oct., 2018 (Redemann et al., 2020). The southeast Atlantic (SEA) is an ideal region for cloud-aerosol effects research because seasonal biomass burning aerosol (BBA) plumes from the African continent subside onto a semipermanent stratocumulus cloud deck (Adebiyi and Zuidema, 2016; Garstang et al., 1996), where they may entrain into the marine boundary layer. The study accumulated over 300 hours of in-situ measurements (corresponding to $\sim 140,000$ linear $\mathrm{km}$ for an airspeed of $250 \mathrm{knots}$ ) at $1 \mathrm{~Hz}$ frequency in the MBL and overlying troposphere from 70 $\mathrm{m}$ up to $6 \mathrm{~km}$. The dataset captures numerous MBL states and cloud layers with varying degrees of BBA loading, as well as cases where the MBL was in contact with both high and low BBA loaded layers in the overlying

65 troposphere.

Isotope ratios were collected with the new Water Isotope System for Precipitation and Entrainment Research (WISPER). The objective of this paper is to describe WISPER and the extensive isotope ratio dataset. Section 2 describes the sampling region and strategy, section 3 introduces WISPER, and section 4 covers calibration methods. Section 5 covers measurement uncertainties and suggested usage of the data. Section 6 uses the data to present the

70 mean moisture and isotopic characteristics of the study region, along with examples of individual vertical profiles. Section 7 provides a few summary remarks.

\section{ORACLES sampling region and climatology}

An extensive overview of the ORACLES project is presented in Redemann et. al. (2020). Aspects of the project that provide relevant context for the isotopic datasets are outlined below. In-situ sampling aboard the NASA P3-Orion aircraft spanned the SEA MBL and lower troposphere (LT) during the agricultural burning season in subtropical southern Africa over southern hemisphere spring. During this season, BBA loaded air in the African PBL is carried out over the SEA by lower troposphere easterly flow (Adebiyi and Zuidema, 2016; Garstang et al., 1996). This air is brought over the SEA cloud deck due to large scale subsidence, where it may then entrain into the MBL. The largescale subsidence also plays a role in the strong inversion topped MBLs of the region. The MBLs then transition to decoupled boundary layers toward the equator as sea surface temperatures (SSTs) increase (Wood, 2012 and references therein). The collected datasets were designed to capture this system.

Sampling flight tracks are shown in Fig. 1. Sampling usually spanned the altitude range $100 \mathrm{~m}$ to $6 \mathrm{~km}$, covering the MBL and the region of the LT where BBA plumes were present. Flight maneuvers included horizontal level legs,

85 "saw-tooth" profiles through cloud layers and at plume boundaries, and vertical profiling via either ramps or square spirals. For more information on aircraft sampling strategies and maneuvers for each flight, Redemann et. al. (2020) provide several useful tables and figures. Their Table 2 and Fig. 12 explain the types of sampling flight maneuvers performed. Their tables A1a, A2, and A3 provide brief summaries of sampling activities for each P3 flight along with the number of repetitions for each flight maneuver.

90 Sampling took place over the three time periods: Aug. 27 - Sept. 27, 2016 (15 flights); Aug. 09 - Sept. 02 , 2017 (14 flights); and Sept. 24 - Oct 25, 2018 (15 flights). Flights were typically every 2-3 days. Most flights were 7-9 hours in duration and within $7 \mathrm{am}$ to $5: 30 \mathrm{pm}$ local time. Figure 2 provides a summary of flight hours at each km of altitude where WISPER successfully collected data.

\section{The Water Isotope System for Precipitation and Entrainment Research (WISPER)}

WISPER was designed to simultaneously obtain in-situ measurements of total water and cloud water concentrations and their isotope ratios $\mathrm{D} / \mathrm{H}$ and ${ }^{18} \mathrm{O} /{ }^{16} \mathrm{O}$ (schematic shown as Fig. 3). Air entered the $\mathrm{P} 3$ cabin through either a solid diffuser inlet (SDI) (McNaughton et al., 2007), or a counterflow virtual impactor (CVI) (Noone et al., 1988; Twohy 
Dat

al., 1997). The SDI was operated by the Hawaii Group for Environmental Aerosol Research (Howell, et al., 2020) and maintained at near isokinetic flow. Total water measurements (vapor + liquid + ice) were obtained from the SDI. The CVI, adapted from the NSF Gulfstream-V inlet (G-V CVI), isolates the condensed water particles by exploiting their inertia whereas ambient vapor is rejected though dry air counterflow. Air from the inlets passed through transfer lines (labelled in Fig. 3) where a fraction of the flows were diverted to gas-phase isotopic analyzers (Picarro models L-2120fxi and L-2120i).
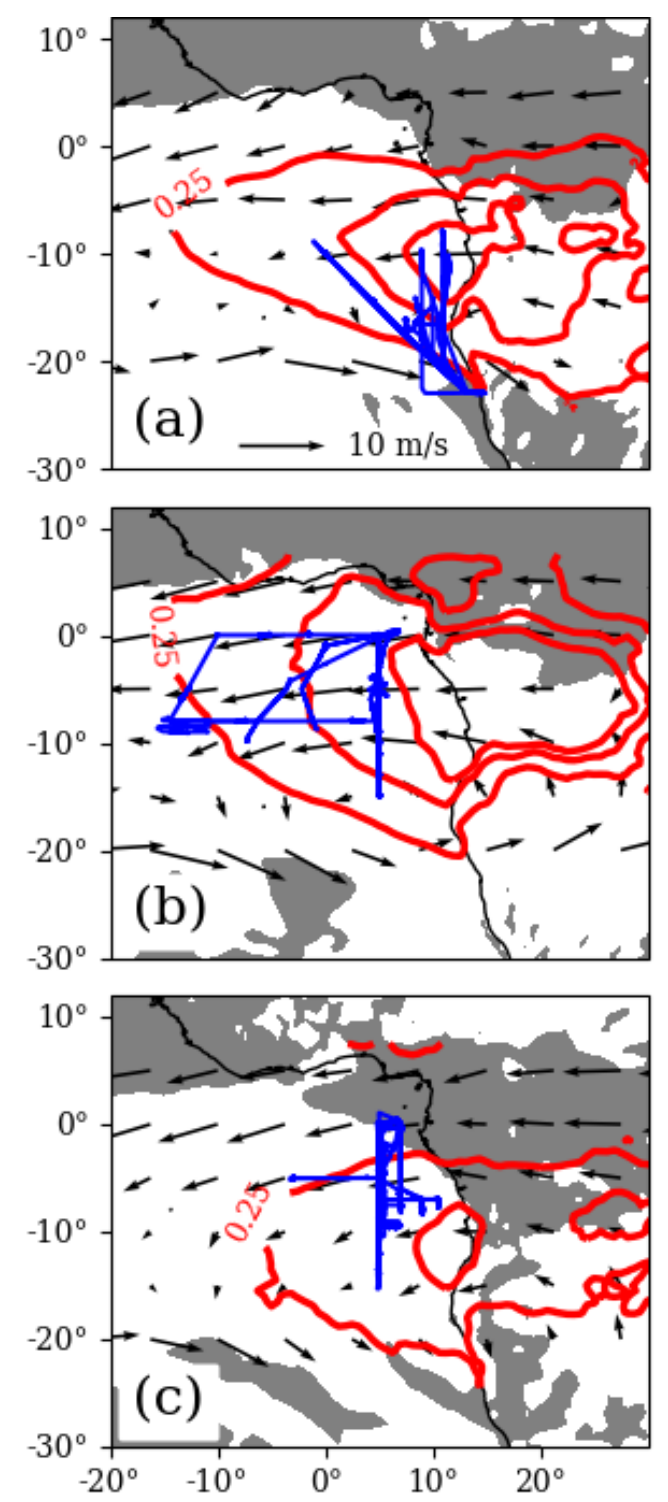

Figure 1: ORACLES P3-Orion flight tracks (blue) for the (a) Sept. 2016, (b) Aug. 2017, and (c) Oct. 2018 sampling periods. MERRA monthly mean aerosol optical depth (red contours, contour intervals are +0.15 going inward) and 500 hPa winds (arrows) between latitudes $25^{\circ} \mathrm{S}$ and $8^{\circ} \mathrm{N}$ are shown. Shading indicates where the MERRA monthly mean 500 hPa vertical velocity is upwards. 
110 Each analyzer measures specific humidity and the isotope ratios $\mathrm{HDO} / \mathrm{H}_{2} \mathrm{O}$ and $\mathrm{H}_{2}{ }^{18} \mathrm{O} / \mathrm{H}_{2} \mathrm{O}$. The first analyzer (Pic1) was able to sample from either the SDI or CVI transfer line. The second analyzer (Pic2) sampled continuously from the SDI line only.

Flow in the SDI transfer line was generated using low pressure provided by a venturi exhaust and maintained at a flow rate of 2 SLPM with an Alicat MC-series mass flow controller (MFC). Flow along the inlet portion of the CVI transfer line was generated by a diaphragm pump and controlled by an Alicat MC-series MFC, modified to use a wider orifice enabling a lower pressure drop for use at high altitude. Total inlet flow through the CVI line could be chosen in-flight between 2-10 SLPM, to provide a desirable cloud sampling enhancement. The dry air counterflow was dynamically adjusted to supply the sum of the bypass flow, air needed for the isotopic gas analyzer and additional flow to supply other instruments used for measuring aerosol, while maintaining the required excess dry air counterflow. For each analyzer, a diaphragm pump was used to divert air from the transfer lines to the analyzer and the flow rate is maintained by an MFC internal to the analyzer. All diaphragm pumps were Vacuubrand MD-1 Vario models. The length of the CVI line from inlet to Pic1 was approximately $1.6 \mathrm{~m}$ and the SDI line from inlet to Pic2 was approximately $6 \mathrm{~m}$. All plumbing lines carrying sample air between the inlets and gas analyzers were 0.25 OD copper, except for a $0.5 \mathrm{~m}$ section of 0.5 OD steel tubing used at the beginning of the CVI plumbing for 2017.
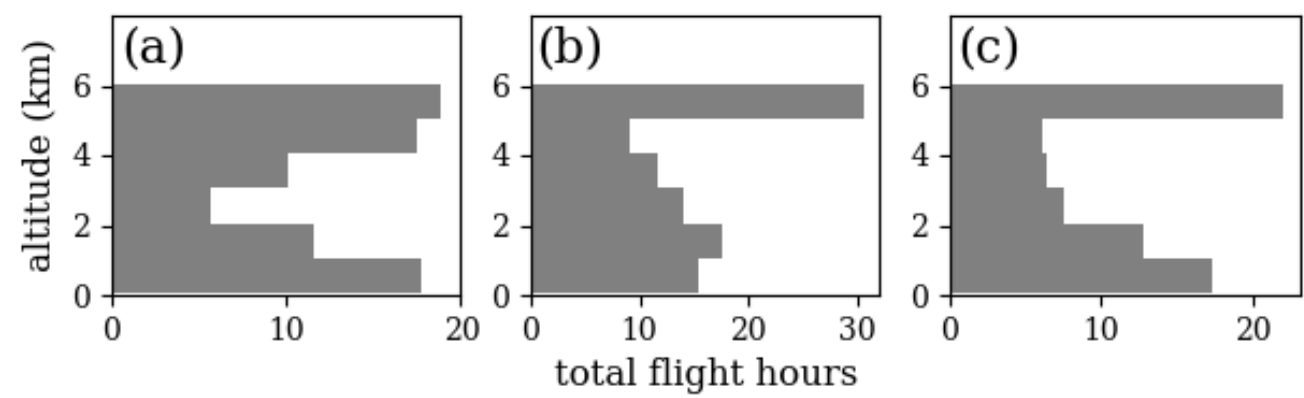

Figure 2: Total flights hours at each $\mathrm{km}$ of altitude where WISPER obtained data at $1 \mathrm{~Hz}$ frequency during the (a) Sept. 2016, (b) Aug. 2017, and (c) Oct. 2018 sampling periods.

The lines between the inlets and the gas analyzers were heated to vaporize any liquid water before sampling. The transfer line to the Pic2 location was heated to $50^{\circ} \mathrm{C}$ by Raychem brand self-regulating heat tape. The CVI transfer line inside the aircraft cabin was heated to a precisely controlled temperature of $65^{\circ} \mathrm{C}$ with Minco model CT325 controllers. Specifically, the CVI transfer line temperature is higher than that on the NSF Gulfstream-V CVI, so as to be confident that droplet vaporization takes place without the likelihood of condensation on cold spots in the sampling lines. The G-V CVI is suspected to have a potential cold point where the sample line enterers the aircraft fuselage, which is possibly responsible for measurement artifacts in cold environments. The WISPER heater 135 arrangement and control logic was designed to overcome, or at least minimize, these types of limitations to avoid possible fractionation artifacts that would result from condensation in the sampling lines. Other differences from the G-V CVI include faster flow control logic and integrated temperature and pressure sensing within the CVI control unit which refines the quality of the measurements. Further details on the WISPER CVI and comparison to the G-V CVI are given in Appendix A.

140 The Picl position for the 2017 and 2018 sampling periods was always occupied by a $5 \mathrm{~Hz}$ instrument (Picarro model L-2120fxi) referred to as 'Mako'. Two $0.5 \mathrm{~Hz}$ instruments (Picarro model L-2120i) referred to as 'Gulper' and 'Spiny' were used in the Pic2 position for 2017 and 2018 respectively. For 2016, no instrument was present in the Picl position. For the 2016 Pic2 position, Mako was used for the first three flights and replaced with Gulper for the remaining flights due to instrument issues. Table 1 shows the WISPER system status for each flight. Data were

145 collected also during test flights, and during transit from the Wallops Flight Facility in Virginia, via Barbados and Ascension Island, to either Walvis Bay in Namibia or Sao Tome. Data from these additional periods are excluded from the primary dataset and the presented data here. 

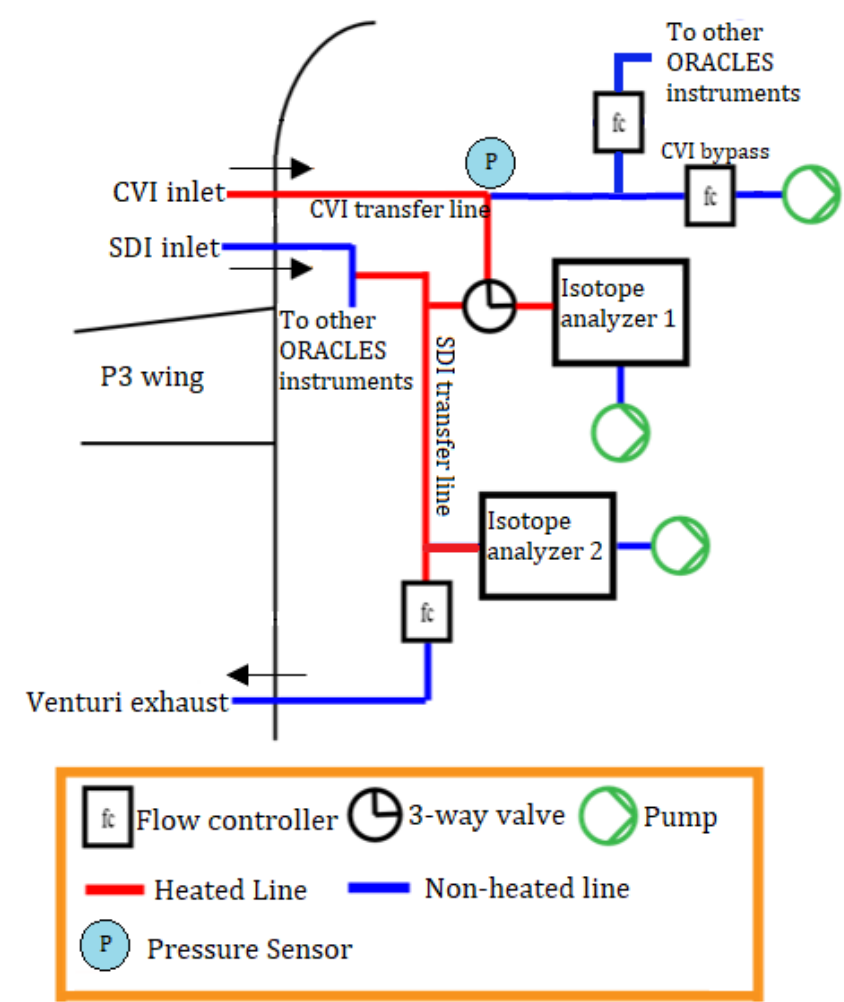

Figure 3: Simplified schematic of the WISPER system on the P3-Orion aircraft. Arrows show direction of airflow. Both isotope analyzers are Picarro-brand cavity ringdown spectrometers. The first analyzer (Pic1) samples off the transfer lines of either a solid differ inlet (SDI) or a counterflow virtual impactor (CVI) inlet, sampling total water or cloud condensed water respectively. The second analyzer (Pic2) samples from the SDI only. Flow in the SDI transfer line is maintained by low pressure from a venturi exhaust. Flow in the CVI transfer line is maintained with a vacuum pump. For each analyzer, air is pulled from the transfer line into the analyzer with a vacuum pump.

\section{Data Processing}

\subsection{Pre-processing and calibration strategy}

160 Over the course of the three-year experiment, three different gas analyzers were used, and each had some degree of technical challenges during each campaign. The calibration and post processing strategy were designed with several aims: 1) ensure time synchronization with other data streams, 2) consistency between the two gas analyzers that were used simultaneously in the Pic1 and Pic2 positions, 3) minimization of known instrumental measurement dependencies (specifically, with respect to dependence on humidity), and 4) ensuring that all relevant errors were

165 accounted for as a core aspect of the resultant datasets. This was best accomplished by aspiring to have one instrument (the highest performing one) very well calibrated, and using it to transfer calibration to the other instruments. In periods when the primary instrument had failures, we were required to use a second instrument to provide absolute calibration. 170 Mako were binned and averaged from the raw $5 \mathrm{~Hz}$ to $1 \mathrm{~Hz}$ frequency using a boxcar weighting function. Data for Gulper and Spiny were linearly interpolated to $1 \mathrm{~Hz}$ from $0.5 \mathrm{~Hz}$. The time series were visually inspected and any data that were clearly erroneous were removed. For the 2018 campaign, Spiny had laser-cavity pressure fluctuations outside the normal operating range once environment pressures dropped below roughly 700 mbar and those data are removed. For Pic1 CVI measurements, data where cloud water content is below $0.01 \mathrm{~g} / \mathrm{kg}$ is not considered reliable 
Table 1: WISPER status for all ORACLES flights.

\begin{tabular}{|c|c|c|c|c|}
\hline $\begin{array}{c}\text { Flight } \\
\text { numbers }\end{array}$ & Dates & Pic1 status & Pic2 status & Notes \\
\hline \multicolumn{5}{|l|}{2016} \\
\hline RF 00 & Aug. 27 & N/A & N/A & Transit flight, data not rigorously calibrated. \\
\hline RF 01-04 & $\begin{array}{l}\text { Aug. 30, 31, } \\
\text { Sept. 02, } 04\end{array}$ & N/A & Mako, Good & No known issues. \\
\hline RF 05 & Sept. 06 & N/A & $\mathrm{N} / \mathrm{A}$ & $\begin{array}{l}\text { Instrument problem detected shortly after } \\
\text { takeoff. No data available. }\end{array}$ \\
\hline RF 06 & Sept. 08 & $\mathrm{~N} / \mathrm{A}$ & $\mathrm{N} / \mathrm{A}$ & No data available. \\
\hline RF 07-11 & $\begin{array}{l}\text { Sept. } 10,12,14 \text {, } \\
\quad 18,20\end{array}$ & N/A & Gulper, Good & $\begin{array}{c}\text { Mako replaced with Gulper. No known } \\
\text { issues. }\end{array}$ \\
\hline RF 12 & Sept. 24 & N/A & Gulper, OK & $\begin{array}{l}\text { There are several time intervals with bad } \\
\text { data, determined later to be associated with } \\
\text { pressure leaks. Data for these intervals have } \\
\text { been removed. }\end{array}$ \\
\hline RF 13 & Sept. 25 & N/A & Gulper, Good & No known issues. \\
\hline RF 14 & Sept. 27 & N/A & Gulper, OK & Transit flight, data not rigorously calibrated. \\
\hline \multicolumn{5}{|l|}{2017} \\
\hline RF 00 & Aug. 09 & Mako, OK & Gulper, OK & Transit flight, data not rigorously calibrated. \\
\hline RF 01-02 & Aug. 12,13 & Mako, OK & Gulper, Good & $\begin{array}{l}\text { Mako cal shifted from normal. Loose } \\
\text { temperature sensor. }\end{array}$ \\
\hline RF 03-05 & Aug. 15, 17, 18 & Mako, Good & Gulper, Good & No known issues. \\
\hline RF 06 & Aug. 19 & N/A & N/A & Flight aborted. \\
\hline RF 07-09 & Aug. $21,24,26$ & Mako, Good & Gulper, Good & No known issues. \\
\hline RF 10 & Aug. 28 & $\begin{array}{l}\text { Mako, } \\
\text { Good/OK }\end{array}$ & Gulper, Good & $\begin{array}{l}\text { Some short time intervals with bad Mako } \\
\text { readings. Bad data removed. }\end{array}$ \\
\hline RF 11-13 & $\begin{array}{c}\text { Aug. 30, 31, } \\
\text { Sept. } 02\end{array}$ & Mako, Good & Gulper, Good & No known issues. \\
\hline \multicolumn{5}{|l|}{2018} \\
\hline RF 00 & Sept. 24 & Mako, OK & Spiny, OK & Transit flight, data not rigorously calibrated. \\
\hline RF 01-02 & Sept. 27, 30 & Mako, Good & $\begin{array}{l}\text { Spiny, } \\
\text { Good/OK }\end{array}$ & No known issues for Pic1. Pic2 data $\mathrm{OK} * \dagger$ \\
\hline RF 03 & Oct. 02 & Mako, Bad & Spiny, Bad & No data available. \\
\hline RF 04 & Oct. 03 & Mako, Good & $\begin{array}{l}\text { Spiny, } \\
\text { Good/OK }\end{array}$ & No known issues for Pic1. Pic2 data OK $* \dagger$ \\
\hline RF 05 & Oct. 05 & Mako, Bad & Spiny, Bad & No data available. \\
\hline RF 06-13 & $\begin{array}{l}\text { Oct. } 07,10,12,15, \\
17, \text { Oct. } 19,21,23\end{array}$ & Mako, Good & $\begin{array}{l}\text { Spiny, } \\
\text { Good/OK }\end{array}$ & No known issues for Pic1. Pic2 data OK $* \dagger$ \\
\hline RF 14 & Oct. 25 & Mako, OK & Spiny, OK & Transit flight, data not rigorously calibrated. \\
\hline
\end{tabular}


and is removed (note that with a CVI enhancement factor of 30 , an actual cloud water content of $0.01 \mathrm{~g} / \mathrm{kg}$ is measured as $0.3 \mathrm{~g} / \mathrm{kg}$ by the analyzer). Isotope data are reported in "delta" notation where $\delta=\left(\mathrm{R} / \mathrm{R}_{\mathrm{s}}-1\right)$, where $\mathrm{R}$ is the heavy to light molar isotope ratio, and $\mathrm{R}_{\mathrm{s}}$ the isotope ratio of the Vienna Standard Mean Ocean Water. Calibration is performed for the $\delta$ values.

\subsection{Time synchronization}

Due to the travel time of air from the sampling inlet to the gas analyzers, the WISPER measurements have a time lag between sampled air's point of inlet entry and point of measurement. To address this, a pressure-dependent time shift was applied which ultimately synchronized the data with one of the wing-mounted cloud probes (chosen as the reference since its measurements are assumed to have minimal lag). Time synchronization to the cloud probes was

185 achieved indirectly by aligning to the COMA instrument (ABB-Los Gatos Research $\mathrm{CO} / \mathrm{CO}_{2} / \mathrm{H}_{2} \mathrm{O}$ analyzer, Liu et al., 2017) after it had been aligned to one of the cloud probes: the Passive Cavity Aerosol Spectrometer Probe (PCASP, Droplet Measurement Technologies, Rosenberg et al., 2012). This allowed COMA-PCASP and COMAWISPER correlated variable pairs to be utilized with a time-lag maximum cross-correlation method; PCASP spikes in BBA are expected to align with COMA spikes in carbon monoxide, while both COMA and WISPER measure

190 specific humidity.

Because the WISPER plumbing was mass-flow controlled, the volumetric flow speed increases with decreasing environment air pressure and the time lag is not constant. Time corrections were formulated as a linear function of pressure. For each flight, WISPER and COMA data were separated into $50 \mathrm{mbar}$ bins. For each bin, the time lag $\Delta \mathrm{t}$ with the maximum cross-correlation between their specific humidity measurements was found. A time correction function $\Delta \mathrm{t}=\mathrm{c}_{1} \mathrm{P}+\mathrm{c}_{2}$ was fit to time lags vs. pressure bins using linear regression, and then applied to the data.

\subsection{Pic1 humidity and isotope ratio calibration}

\subsubsection{Humidity calibration}

Picarro gas analyzers report water abundance proportional to specific humidity (i.e., "wet" mixing ratio measured as the ratio of vapor pressure to total air pressure), fundamentally determined from infrared absorption by $\mathrm{H}_{2} \mathrm{O}$ relative to optical cavity pressure. Specific humidity calibrations were calibrated using a Licor 610 Dew Point Generator (DPG). The DPG was used to produce saturated air at preset (dew point) temperatures between 500 ppmv $(0.31$ $\mathrm{g} / \mathrm{kg}$ ) and 20,000 ppmv (12.5 g/kg), which was then sampled by the gas analyzer. The relationship between Picarromeasured humidity $q_{p i c}$ and DPG-known humidity $q_{D P G}$, was robustly linear $\left(\mathrm{R}^{2}>0.98\right)$, with the same slope use for all ORACLES years:

$q_{D P G}=m_{q} * q_{p i c}$,

where the water concentrations are in units of ppmv. For Mako, $m_{q}=0.851$.

\subsubsection{Correction for humidity dependence of isotope ratios}

Picarro isotope ratio measurements both develop a bias and become less precise as humidity decreases (see e.g.

210 Schmidt et al., 2010; Tremoy et al., 2011). This bias was quantified by using the Picarro to measure air of constant isotope ratios $\left(\delta \mathrm{D}\right.$ and $\left.\delta^{18} \mathrm{O}\right)$ diluted with a progressively higher fraction of ultra-grade dry air (Airgas product AI

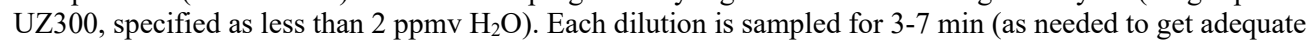
statistics) and the mean is taken. The deviation of both mean $\delta \mathrm{D}$ and $\delta^{18} \mathrm{O}$ from those measured at the highest humidity $(\sim 18,000 \mathrm{ppmv}$, or $\sim 11 \mathrm{~g} / \mathrm{kg})$ was fit with the function:

$215 \Delta \delta_{i}(q)=a_{i} *\left[\ln \left(\frac{50,000}{q[\text { ppmv }]}\right)\right]^{b_{i}}$,

where $q$ is the measured humidity in ppmv, $a$ and $b$ are fit parameters, subscript $i$ is for the isotope species (D or 180 ) and 50,000 ppmv is chosen as an asymptotically high humidity. The calibration parameters do not change significantly if the latter is replaced with 18,000 ppmv. Equation (2) was fit to calibration data separately for each ORACLES year using non-linear least squares regression (Python SciPy's optimize package, Virtanen et al., 2020). Table 2 summarizes calibration data taken for each year and the fit parameters obtained, and Fig. 4 plots the corrections. The calibration for 2017 is different than the other years. This alteration is attributed to a loose thermistor during the 2017 deployment which was temporarily fixed in the field and then permanently reattached before the 2018 deployment. 
Table 2: Parameter values for Equation (2), the humidity dependent bias correction in Picarro measured isotope ratios, with standard errors.

\begin{tabular}{|c|c|c|c|c|c|c|}
\hline $\begin{array}{l}\text { ORACLES } \\
\text { year }\end{array}$ & $\begin{array}{c}\text { Instrument } \\
\text { name }\end{array}$ & Calibration data & ad (\%) & bD & a180 (\%o) & $b_{180}$ \\
\hline 2016 & Mako & $\begin{array}{c}3 \text { laboratory runs over } \\
\text { May, } 2017\end{array}$ & $-0.37 \pm 0.056$ & $3.03 \pm 0.16$ & $-0.006 \pm 0.0015$ & $4.96 \pm 0.21$ \\
\hline 2017 & Mako & $\begin{array}{l}4 \text { runs in the field over a } \\
\text { 10-day period during } \\
\text { ORACLES } 2017\end{array}$ & $-0.44 \pm 0.098$ & $2.18 \pm 0.29$ & $-0.013 \pm 0.0071$ & $3.71 \pm 0.53$ \\
\hline 2018 & Mako & $\begin{array}{l}1 \text { run in the field during } \\
\text { ORACLES } 2018\end{array}$ & $-0.33 \pm 0.085$ & $2.86 \pm 0.25$ & $-0.006 \pm 0.0056$ & $4.58 \pm 0.67$ \\
\hline 2016 & Gulper & $\begin{array}{c}2 \text { laboratory runs in } \\
\text { May, } 2017\end{array}$ & $0.035 \pm 0.008$ & $4.46 \pm 0.19$ & $0.067 \pm 0.014$ & $1.89 \pm 0.20$ \\
\hline
\end{tabular}

\subsubsection{Absolute calibration of isotope ratios}

Measurements were placed on an absolute scale using several water standards for which the isotope ratio was known (Coplen, 1994). Standard waters (Table 3) were secondary standards based on Florida deionized tap water and "polar" water (a mixture of Antarctic surface snow, mostly from the West Antarctic Ice Sheet). Each was prepared in stainless a steel keg and isotope ratios were measured by the University of Colorado Stable Isotope Laboratory with reference to the International Atomic Energy Agency scale.
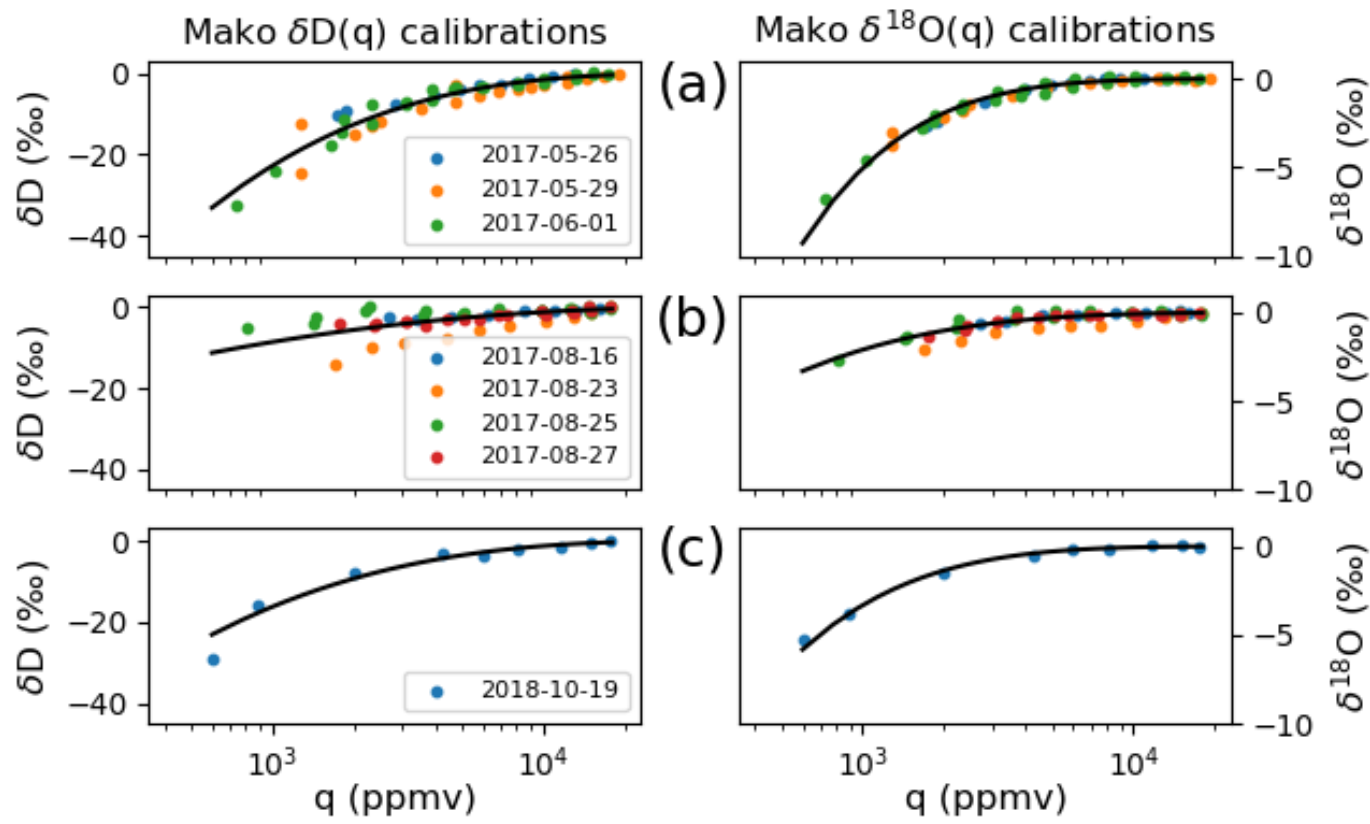

Figure 4: Mako isotope ratio humidity-dependence corrections for ORACLES (a) 2016, (b) 2017, and (c) 2018. Data points are colored by date that the calibration was performed. Fit curves are generated using nonlinear regression with Eqn. 2.

Calibrations for each instrument were performed in the laboratory before the first field deployment. Standards were injected by syringe into a Picarro vaporization module and then sampled by the gas analyzers. The relationship 
between measured and actual $\delta$ was taken to be linear from previous field deployments (following, e.g., Noone et al., 2013; Bailey et al., 2016), and a 2-point calibration was performed to obtain the slope and offset. The linear fits are:

$\delta D_{\text {cal }}=1.056 * \delta D^{\prime}+5.96$,

$\delta^{18} O_{\text {cal }}=1.052 * \delta^{18} O^{\prime}+1.04+f$,

where the prime superscript refers to data which has had the humidity-dependence correction applied (Eqn. 2). The $f$ in Eqn. $3 \mathrm{~b}$ is a semi-objective adjustment term (offset), ranging 1-3\%o, which corrects for observed drift in $\delta^{18} \mathrm{O}$ over the 3 years when comparing histograms of $\mathrm{P} 3$ data collected below $500 \mathrm{~m}$ in altitude. $\delta \mathrm{D}$ does not show this drift. Additionally, deuterium excess $\left(d x s=\delta \mathrm{D}-8 \delta^{18} \mathrm{O}\right)$ maxima are anomalously high in 2016 and 2017 when compared to previous studies, in proportion with the $\delta^{18} \mathrm{O}$ drift. We suspect the primary origin of the drift to be slow degradation of the optical system resulting from sampling in the highly polluted biomass burning plume (BBA concentrations were higher in 2016 and 2017 then in 2018), with the design of the Picarro optical cavity excluding the possibility for mirrors to be cleaned. Previous studies in the Atlantic suggest that the $d x s$ peak is typically observed be between 12-18\%o (Benetti et al., 2017), and therefore we chose $f$ to bring $d x s$ into this range, while being faithful to our estimates of absolute calibration. The manner in which this uncertainty was accounted for is discussed in Section 5.

Table 3: Isotope standards used for Picarro calibrations.

\begin{tabular}{lll}
\hline Standard & $\boldsymbol{\delta D}$ & $\boldsymbol{\delta}^{\mathbf{1 8}} \mathbf{O}$ \\
\hline Florida tap water & $-3.56 \pm 0.07$ & $-0.95 \pm 0.06$ \\
Antarctica surface snow & $-235.3 \pm 0.26$ & $-29.74 \pm 0.025$ \\
\hline
\end{tabular}

\subsection{Pic2 humidity and isotope ratio calibration}

\subsubsection{Cross-calibration in 2017 and 2018}

For 2017 and 2018, both Pic1 and Pic2 were present in the WISPER system. Pic1 and Pic2 measured from the same inlet for the majority of each flight, except for when Pic1 was switched to the CVI in-cloud. For these years, Pic2 was cross-calibrated to Pic1. Cross-calibration was chosen over absolute calibration to ensure that the relative changes in total water and cloud water isotope ratios are as accurate as possible. The ability to compare the relative difference between these two measurements was, by design, the scientific target.

For both 2017 and 2018, the relationship between Pic1 and Pic2 specific humidity follow a line $\left(\mathrm{R}^{2}>0.99\right)$ that passes through the origin, with slopes of 0.9077 and 1.1007 respectively. For $\delta \mathrm{D}$ measurements, Pic $1 \delta \mathrm{D}$ was

265 modeled as a polynomial of Pic2-measured $q$ and $\delta \mathrm{D}$, and likewise for $\delta^{18} \mathrm{O}$. Let $\delta_{1}$ denote a Pic1 isotope ratio measurement ( $\delta \mathrm{D}$ or $\delta^{18} \mathrm{O}$ ), and $q_{2}, \delta_{2}$ denote Pic2 humidity and isotope-ratio measurements. The following polynomial was fit using linear regression (Python statsmodels, Seabold \& Perktold, 2010):

$\delta_{1}=\sum_{i}^{n_{q}}\left[c_{q i} \ln \left(q_{2}\right)^{i}\right]+\sum_{j}^{n_{\delta}}\left[c_{\delta j} \delta_{2}^{j}\right]+\sum_{k}^{n_{x}}\left[c_{x k}\left(\ln \left(q_{2}\right) \delta_{2}\right)^{k}\right]$,

where the last term is a cross-term and $c_{q i}, c_{\delta \mathrm{j}}$, and $\mathrm{c}_{\mathrm{xk}}$ are linear fit parameters. The orders of the polynomials $\mathrm{n}_{\mathrm{q}}, \mathrm{n}_{\delta}$, and $\mathrm{n}_{\mathrm{x}}$ were chosen to minimize the Bayesian information criterion but capped at order 5 . Figure 5 shows the results of the fit for 2017. Both the fits for $\delta \mathrm{D}$ or $\delta^{18} \mathrm{O}$ have $\mathrm{R}^{2}>0.95$. Similar results are obtained for 2018 (Fig. 6), with the fits for each isotope ratio having $\mathrm{R}^{2}>0.93$. Root-mean-squared-errors for both years and for $q>4 \mathrm{~g} / \mathrm{kg}$ (where the Pic2 data are most relevant) are $2 \%$ for $\delta \mathrm{D}$ and $0.4 \%$ for $\delta^{18} \mathrm{O}$.

\subsubsection{Calibration in 2016}

275 For 2016, only one instrument (in the Pic2 position) was present. For the first three flights this position was filled by Mako, for which the calibration procedure is as detailed in Section 4.4. For the remaining 2016 flights with available data, the position was filled by Gulper. The calibrations follow Eq. (1)-(3) analogous to Mako. For Gulper, Eq. (1) $m_{q}=0.909$. Parameters for Gulper $\delta$ (q) (Eq. 2) are given in Table 3. For Eq. (3), a 2-point calibration was performed in the lab between the 2016 and 2017 deployments, for which the slopes $\left(1.094\right.$ for $\delta \mathrm{D}$ and 1.068 for $\left.\delta^{18} \mathrm{O}\right)$ are

280 trusted but not so much the offsets. Therefore, an alternate estimate of the offset is obtained by comparing histogram peaks of Gulper sub-cloud layer measurements to those of Mako measurements over similar flight tracks. This relies on the assumption that for similar synoptic conditions these two peaks should roughly coincide. Further details are 
given in the appendix. The resulting offsets are $28 \%$ for $\delta \mathrm{D}$ and $6.3 \%$ for $\delta^{18} \mathrm{O}$. The uncertainties associated with this method are discussed below.
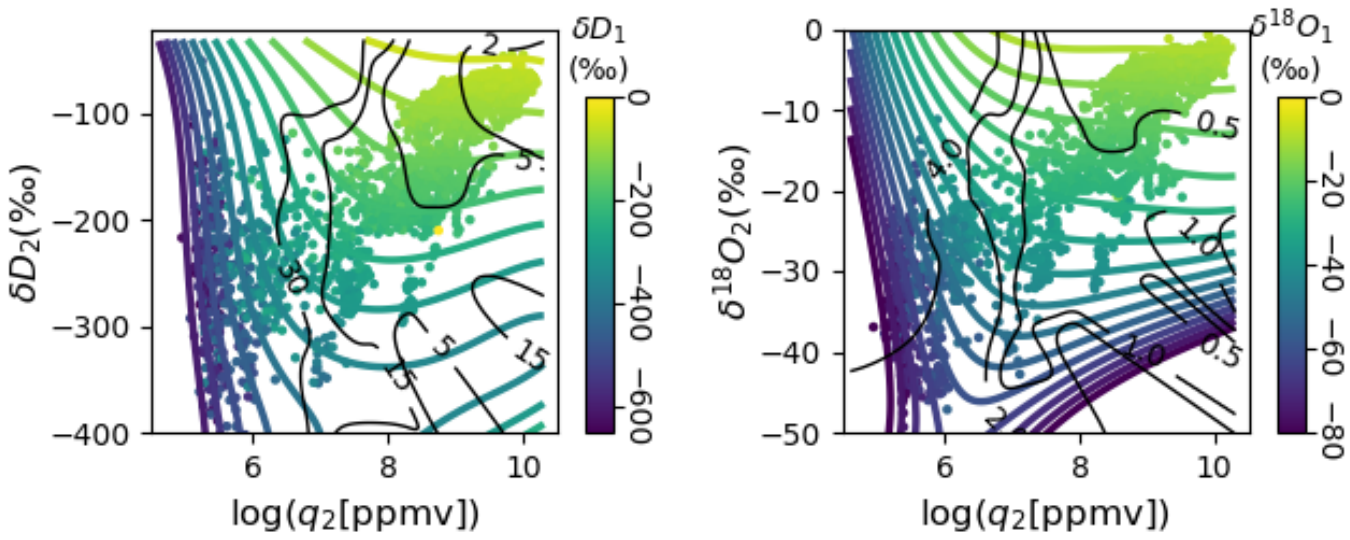

Figure 5: Cross-calibration of Pic2 to Pic1 for the 2017 sampling period. (a): Pic1 $\delta D$ vs Pic2 $\log (q)$ and $\delta D$ (scatter) with model-fit (colored contours). (b): Same as (a) but for $\delta^{18} O$. Both fits have $R^{2}>0.95$. Root-mean-squared-errors for $q>4$ $\mathrm{g} / \mathrm{kg}$ (where the Pic2 data are most relevant) are $2 \%$ for $\delta \mathrm{D}$ and $0.4 \%$ for $\delta^{18} \mathrm{O}$. Black contours are model residuals.
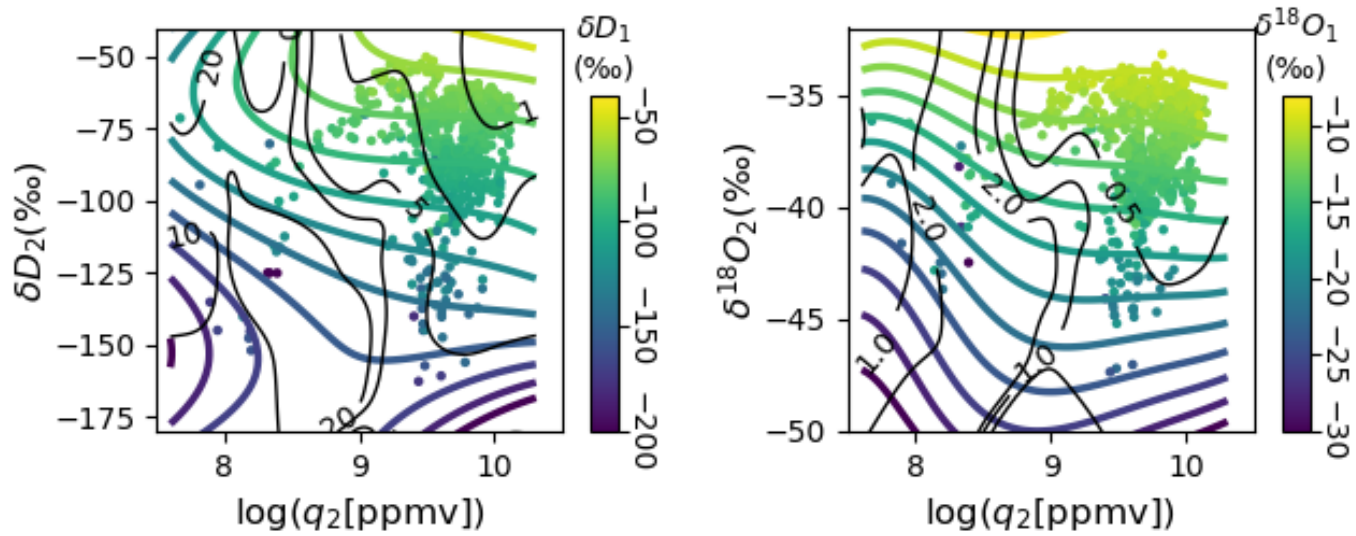

290 Figure 6: Same as Fig. 5 but for the 2018 sampling period, during which there was a narrower range of $q$ and dD available for cross calibration compared to 2017 . Both fits have $R^{2}>0.93$. Root-mean-squared-errors for $q>4 \mathrm{~g} / \mathrm{kg}$ are $2 \%$ for $\delta \mathrm{D}$ and $0.4 \%$ for $\delta^{18} \mathrm{O}$.

\section{Measurement uncertainties and suggested data usage}

\subsection{Suggested use and uncertainty quick reference}

Unless the user is familiar with Picarro measurements or has consulted the authors, it is recommended that the data be averaged to 10 second averages $(0.1 \mathrm{~Hz}$ frequency), at which point each measurement can be considered independent. It is also recommended that SDI data collected at humidity $<0.5 \mathrm{~g} / \mathrm{kg}$ are excluded from primary analyses. Note that for CVI data with an enhancement factor of $\sim 30$, measured water concentrations of $0.5 \mathrm{~g} / \mathrm{kg}$ correspond to an actual cloud water content of $0.017 \mathrm{~g} / \mathrm{kg}$. Pic1 data (variables ending in either "_tot1" or "_cld" in the datafiles, standing for total water and cloud water quantities respectively) should be used wherever available since the $5 \mathrm{~Hz}$ instrument which occupied the Picl position has a faster sampling time and resolves smaller features. Additionally, both the calibration and uncertainties for Pic1 are better known than for Pic2, and therefore the Pic1 
data should be used as a preference. The 10 second average during typical ascents and descents of $1000 \mathrm{ft} / \mathrm{minute}$ corresponds to approximately 50 meter vertical resolution for profiles. Many of the in-cloud profiles were performed at $500 \mathrm{ft} / \mathrm{second}$, for improved vertical resolution. The Pic2 data is most useful for times where Pic1 is on the CVI and one wants in-cloud total water measurements to compare to the condensed cloud water measurements. The only exception to the above is for the flights on August $12^{\text {th }}$ and $13^{\text {th }}, 2017$. Pic 1 experienced problems on those days and it is suspected its calibration was altered. Therefore it is recommended that Pic 2 data is used for those two days.

310 Lastly, the transit flights listed in Table 1 should not be used for most analyses, as they have been minimally processed.

As detailed in the next section, a full accounting for uncertainties in $\delta \mathrm{D}$ and $\delta^{18} \mathrm{O}$ involves a lengthy function of $\mathrm{q}$ and the $\delta$ values themselves. However, for many studies the values quoted in tables $4 \mathrm{a}(\mathrm{Pic} 1)$ and $4 \mathrm{~b}$ (Pic2) will suffice. They are given for four typical situations experienced in ORACLES: high humidity MBLs, moderate

315 humidity in the FT (typically when sampling BB-plumes), low humidity FT, and very low humidity FT.

Table 4a: Characteristic Pic1 isotope ratio errors (i.e. $+/-2 \sigma$ gives $95 \%$ confidence intervals) for four typical situations observed in ORACLES. These include MBL sampling and FT sampling at a few humidities (the $q$ and $\delta$ values under each header are typical values observed in that situation). Additionally, values for two separate use cases are included: studies looking at relative trends in the ORACLES WISPER dataset vs. comparison of this dataset to others or to theory.

\begin{tabular}{|c|c|c|c|c|c|c|c|c|}
\hline \multirow[b]{2}{*}{ use case } & \multicolumn{2}{|c|}{$\begin{array}{c}\text { MBL } \\
\mathrm{q} \sim 13 \mathrm{~g} / \mathrm{kg} \\
\delta \mathrm{D} \sim-70 \% \\
\delta^{18} \mathrm{O} \sim-10 \%\end{array}$} & \multicolumn{2}{|c|}{$\begin{array}{c}\text { Moderate } \\
\text { humidity FT } \\
\mathrm{q} \sim 4 \mathrm{~g} / \mathrm{kg} \\
\delta \mathrm{D} \sim-100 \% \\
\delta^{18} \mathrm{O} \sim-14 \% \mathrm{o}\end{array}$} & \multicolumn{2}{|c|}{ 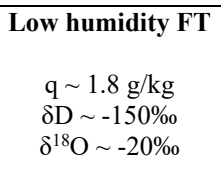 } & \multicolumn{2}{|c|}{$\begin{array}{c}\text { Very low } \\
\text { humidity FT } \\
\mathrm{q} \sim 1 \mathrm{~g} / \mathrm{kg} \\
\delta \mathrm{D} \sim-250 \% 0 \\
\delta^{18} \mathrm{O} \sim-34 \% \mathrm{o}\end{array}$} \\
\hline & $\sigma_{\mathrm{D}}$ & $\sigma_{180}$ & $\sigma_{D}$ & $\sigma_{180}$ & $\sigma_{D}$ & $\sigma_{180}$ & $\sigma_{\mathrm{D}}$ & $\sigma_{180}$ \\
\hline $\begin{array}{l}0.1 \mathrm{~Hz} \text { data; comparisons of } \\
\text { ORACLES WISPER data to itself. } \\
\text { E.g. relative trends in the data not } \\
\text { requiring an absolute scale. }\end{array}$ & $1.8 \%$ & $0.4 \%$ & $2.7 \%$ & $0.5 \%$ & $4.5 \%$ & $0.7 \%$ & $10 \%$ & $1.3 \%$ \\
\hline $\begin{array}{l}0.1 \mathrm{~Hz} \text { data; comparison to other } \\
\text { datasets or to theory. }\end{array}$ & $4.3 \%$ & $1.2 \%$ & $5.5 \%$ & $1.3 \%$ & $6.5 \%$ & $1.3 \%$ & $11 \%$ & $2.0 \%$ \\
\hline
\end{tabular}

Table 4b: Same as Table 4a but for Pic2 measurements.

\begin{tabular}{|c|c|c|c|c|c|c|c|c|}
\hline \multirow[b]{2}{*}{ use case } & \multicolumn{2}{|c|}{$\begin{array}{c}\text { MBL } \\
\mathrm{q} \sim 13 \mathrm{~g} / \mathrm{kg} \\
\delta \mathrm{D} \sim-70 \% \\
\delta^{18} \mathrm{O} \sim-10 \% \mathrm{o}\end{array}$} & \multicolumn{2}{|c|}{$\begin{array}{c}\text { Moderate } \\
\text { humidity FT } \\
\mathrm{q} \sim 4 \mathrm{~g} / \mathrm{kg} \\
\delta \mathrm{D} \sim-100 \% 0 \\
\delta^{18} \mathrm{O} \sim-14 \%\end{array}$} & \multicolumn{2}{|c|}{$\begin{array}{c}\text { Low humidity FT } \\
\begin{array}{c}\mathrm{q} \sim 1.8 \mathrm{~g} / \mathrm{kg} \\
\delta \mathrm{D} \sim-150 \% 0 \\
\delta^{18} \mathrm{O} \sim-20 \%\end{array}\end{array}$} & \multicolumn{2}{|c|}{$\begin{array}{c}\text { Very low } \\
\text { humidity FT } \\
\mathrm{q} \sim 1 \mathrm{~g} / \mathrm{kg} \\
\delta \mathrm{D} \sim-250 \% 0 \\
\delta^{18} \mathrm{O} \sim-34 \% 0\end{array}$} \\
\hline & $\sigma_{D}$ & $\sigma_{180}$ & $\sigma_{D}$ & $\sigma_{180}$ & $\sigma_{D}$ & $\sigma_{180}$ & $\sigma_{D}$ & $\sigma_{180}$ \\
\hline $\begin{array}{l}0.1 \mathrm{~Hz} \text { data; comparisons of } \\
\text { ORACLES WISPER data to itself. } \\
\text { E.g. relative trends in the data not } \\
\text { requiring an absolute scale. }\end{array}$ & $2.7 \%$ & $0.6 \%$ & $3.4 \%$ & $0.6 \%$ & $5.4 \% 0$ & $0.9 \%$ & $10.8 \%$ & $1.5 \%$ \\
\hline $\begin{array}{l}0.1 \mathrm{~Hz} \text { data; comparison to other } \\
\text { datasets or to theory. }\end{array}$ & $4.6 \%$ & $1.3 \%$ & $5.9 \%$ & $1.4 \%$ & $7.2 \% 0$ & $1.4 \%$ & $11.7 \%$ & $2.2 \%$ \\
\hline
\end{tabular}

\subsection{Detailed uncertainty estimation}

Monte Carlo methods were used to propagate all known uncertainties in the Pic1 parameter fits for Eq. (2) and (3), as well as instrument precisions, to produce estimates of total uncertainties for the full range of measured $q$ and isotope ratios. The parameters are uncorrelated and therefore parameter space was sampled using Gaussian distributions centered on parameter expected values and with standard deviations equal to their standard errors. For 
instrument precision, a Gaussian with standard deviation equal to the instrument precision is sampled. Output was generated over the range of observed $q$ and isotope ratios during ORACLES. Monte Carlo simulations using the ORACLES 2016 parameter fits and errors are used but the results are applicable to all years. Separate simulations of 8,000 iterations each were run for three use cases:

1. Relative comparison of $1 \mathrm{~Hz}$ data (relative trends in the data, not on absolute scale).

2. Relative comparison of data averaged to $0.1 \mathrm{~Hz}$ (relative trends in the data, not on absolute scale).

3. Comparison of data averaged to $0.1 \mathrm{~Hz}$ with other datasets or to theory on an absolute scale.

The uncertainties are a function of both $\mathrm{q}$ and the respective $\delta$. For all use cases, the Monte Carlo-derived standard deviations were fit to the following function with $\mathrm{R}^{2}$ of 0.98 or better:

$\sigma_{i}=\alpha_{0}+\alpha_{1} \log (q)+\alpha_{2} \log (q)^{2}+\alpha_{3} \log (q)^{3}+\alpha_{4} \log (q)^{4}+\alpha_{5} \delta_{i}$,

where subscript $i$ is for the isotopologue and $q$ is in units of ppmv. The values of the fit parameters $\alpha_{0}-\alpha_{5}$ are given in Table 5. If the user desires Pic1 uncertainty estimations more detailed than those given in Table 4a, they should compute them using Eqn. 5 and Table 5.

340 Equation 5 is applicable to Pic1 for the 2017 and 2018 sampling periods and to Pic 2 for 2016, but does not account for errors in Pic2 measurements from cross-calibration. It was considered adequate to estimate uncertainties for Pic2 by adding the cross-calibration variance to the Pic1 variance for isotope species $i$ :

$\sigma_{\mathrm{i}, \mathrm{Pic} 2}(q, \delta)=\left[\sigma_{\mathrm{i}, \mathrm{Pic} 1}^{2}(q, \delta)+\sigma_{\mathrm{i}, \mathrm{xcal}}^{2}\right]^{1 / 2}$,

While the cross-calibration variance $\sigma_{\mathrm{i}, \mathrm{xcal}}{ }^{2}$ technically depends on $q$ and $\delta \mathrm{D}$, the dependence is small for $q>4 \mathrm{~g} / \mathrm{kg}$ and can be taken as a constant $2 \%$ for $\delta \mathrm{D}$ and $0.4 \%$ for $\delta^{18} \mathrm{O}$ (the root-mean-squared-errors from the crosscalibration for $q>4 \mathrm{~g} / \mathrm{kg}$ ). Since the primary use of Pic2 data is in the MBL (to compare to Pic1 cloud water measurements), those constant values are appropriate for most studies.

Table 5: Parameter values to use with Eqn. 6 to obtain standard errors in Pic1 isotope ratios, if more detailed error estimations than those given in Table $4 \mathrm{a}$ are desired. The three use cases are described in the main text.

\begin{tabular}{cccccccc}
\hline use case & isotopologue & $\boldsymbol{\alpha 0}$ & $\boldsymbol{\alpha 1}$ & $\boldsymbol{\alpha 2}$ & $\boldsymbol{\alpha 3}$ & $\boldsymbol{\alpha 4}$ & $\boldsymbol{\alpha 5}$ \\
\hline 1 & $\delta \mathrm{D}$ & 1285 & -522.9 & 80.24 & -5.496 & 0.1417 & -0.024 \\
& $\delta^{18} \mathrm{O}$ & 334.4 & -142.6 & 22.91 & -1.64 & 0.0441 & -0.0142 \\
2 & $\delta \mathrm{D}$ & 632 & -267.5 & 42.42 & -2.986 & 0.0788 & -0.0278 \\
& $\delta^{18} \mathrm{O}$ & 434.1 & -189.8 & 31.12 & -2.265 & 0.0617 & -0.0169 \\
\multirow{2}{*}{3} & $\delta \mathrm{D}$ & 568.5 & -242.1 & 38.83 & -2.766 & 0.0738 & -0.0209 \\
& $\delta^{18} \mathrm{O}$ & 285 & -125 & 20.63 & -1.511 & 0.0414 & -0.0079 \\
\hline
\end{tabular}

\subsection{A note on uncertainties for Eq. (3) parameters}

The isotope ratio uncertainty estimations above require values for standard errors on the calibration parameters. While robust estimates of those parameters exist for Eq. (2), inadequate high quality calibration data was obtained to constrain them for Eq. (3) (see Sections 4.3.3 and 4.4.2). Under normal circumstances the calibration slope is robust

355 (e.g., Bailey et al 2016), but between the loose thermistor in 2017 and the drift in $\delta^{18} \mathrm{O}$, it is appropriate to provide conservative estimates of $\sigma_{m i}$ and $\sigma_{k i}$ (standard errors in the Eq. (3) slope and offset for isotope species $i$ ). For $\sigma_{m i}$, we account for a possible doubling of the deviation of the slopes in Eq. (3) from unity. For example, the Pic1 slope in $\delta \mathrm{D}$ is 1.056 (deviation from unity of 0.056 ) and therefore we construct a $m_{D} 95 \%$ confidence interval [ 1 , $1+2 * 0.056]$ (i.e. $\sigma_{m i}=0.056 / 2$ ). For $\sigma_{k i}$, we prescribe different values for the three use cases in the previous section.

360 For the first two, we only care about relative drifts between the years. $\delta \mathrm{D}$ did not drift much and so $\sigma_{k, D}$ was assigned $1 \%$. $\delta^{18} \mathrm{O}$ on the other hand clearly drifted, and $\sigma_{k, 18 O}$ was assigned $0.5 \%$ (which is roughly the standard deviation of a $\delta^{18} \mathrm{O}$ histogram constructed from data in the sub-cloud well-mixed layer). For the third case, we care about absolute offsets. We assign $\sigma_{k, D}=4 \%, \sigma_{k, 180}=1 \%$, which give $95 \%$ confidence intervals of $+/-8 \%$ and $+/-2 \%$ even before including the other parameter uncertainties. Based on variability in marine near-surface measurements (outlined in Benetti et al., 2017 as well as our own), this was considered conservative. 


\section{Data and illustrative examples}

\subsection{Near-surface and free-troposphere isotope ratios}

Table 6 gives intervals in which $95 \%$ of the WISPER measurements fall after averaging the $1 \mathrm{~Hz}$ data into $10 \mathrm{~s}$ blocks. The data are split into two general regions. All data below $500 \mathrm{~m}$ were assumed to be in the sub-cloud wellmixed layer, while all data above $2500 \mathrm{~m}$ were assumed to be predominantly above the MBL (see figures 7,8 , and 9).

The data below $500 \mathrm{~m}$ are compared to previous studies which used ship based, near-surface measurements. Benetti et al. (2017) summarize five cruises in the Atlantic Ocean which collected water vapor isotope measurements. Leaving out the ACTIV cruise, which had exceptionally negative delta-values, the cruises find $\delta^{18} \mathrm{O}$ typically in the range $(-15 \%,-9 \%), \delta \mathrm{D}$ in the range $(-60 \%,-110 \%)$, and $(-5 \%, 25 \%)$ for $d x s$ (which we inferred from their Fig. 5). These ranges agree well with our measurements (Table 6). Although the 2016 and 2017 ORACLES $\delta^{18} \mathrm{O}$ measurements were purposely given a constant offset so that histogram peaks of near surface $d x s$ were $\sim 15 \%$, this does not affect the width of the $\delta^{18} \mathrm{O}$ or $d x s$ intervals, which either agree with or are narrower than the cruise data. As another example, Pfahl and Sodemann 2014 Fig. la shows ship-based measurements of $d x s$ from studies in the Mediterranean Sea (Gat et al., 2003) and Southern Ocean (Uemura et al., 2008) with ranges of (10\%, $30 \%$ ) and ($5 \%, 30 \%$ ) respectively. Again, the ORACLES mixed-layer $d x s$ measurements fall within these ranges.

Table 6: Intervals in which $95 \%$ of the WISPER measurements fall after averaging the $1 \mathrm{~Hz}$ data into $10 \mathrm{~s}$ blocks, given separately for each ORACLES sampling period.

\begin{tabular}{c|ccc|ccc}
\hline $\begin{array}{c}\text { ORACLS } \\
\text { year }\end{array}$ & \multicolumn{3}{|c|}{ height $<\mathbf{5 0 0 m}$} & \multicolumn{3}{c}{ height $>\mathbf{2 5 0 0 m}, \mathbf{q}>\mathbf{1} \mathbf{g} / \mathbf{k g}$} \\
\hline & $\mathbf{\delta D}$ & $\boldsymbol{\delta}^{\mathbf{1 8}} \mathbf{O}$ & $\mathbf{d x s}$ & $\boldsymbol{\delta D}$ & $\boldsymbol{\delta}^{\mathbf{1 8} \mathbf{O}}$ & $\mathbf{d x s}$ \\
2016 & $-84.0,-61.9$ & $-12.2,-10.0$ & $8.4,24.7$ & $-176.1,-66.6$ & $-22.5,-10.6$ & $-9.8,25.6$ \\
2017 & $-81.0,-62.7$ & $-12.9,-9.6$ & $5.4,25.7$ & $-279.8,-65.1$ & $-37.4,-10.3$ & $3.6,26.8$ \\
2018 & $-101.8,-70.2$ & $-14.6,-10.1$ & $6.2,20.5$ & $-322.3,-68.8$ & $-42.9,-10.6$ & $4.0,24.6$ \\
\hline
\end{tabular}

\begin{tabular}{c|ccc}
\hline $\begin{array}{c}\text { ORACLS } \\
\text { year }\end{array}$ & \multicolumn{4}{|c}{ height $>\mathbf{2 5 0 0 m}, \mathbf{q}>\mathbf{0 . 2 5} \mathbf{~ g / k g}$} \\
\hline & $\boldsymbol{\delta D}$ & $\boldsymbol{\delta}^{\mathbf{1 8}} \mathbf{O}$ & $\mathbf{d x s}$ \\
2016 & $-354.0,-72.3$ & $-44.7,-11.3$ & $-46.2,25.7$ \\
2017 & $-306.6,-67.6$ & $-40.6,-10.6$ & $3.7,29.1$ \\
2018 & $-344.9,-72.7$ & $-45.6,-11.1$ & $4.3,24.8$ \\
\hline
\end{tabular}

The LT values above the MBL can reach much lower values, which is expected. Remarkably, within the BBA plumes, isotope ratios that are similar to those of the mixed layer are evident, consistent with the expectation that air originating from over the African contains water vapor dominated by surface-level isotope ratios. For the $q>1 \mathrm{~g} / \mathrm{kg}$ data, the lower bounds of $\delta \mathrm{D}$ and $\delta^{18} \mathrm{O}$ decrease noticeably from 2016 to 2018 . It was assumed that we sampled 390 increasingly more convective activity from 2016 to 2018 and so the lower isotope ratios in those years may result from more frequent Rayleigh distillation-like processes associated with precipitation. The range in $d x s$ for 2017 and 2018 is almost unchanged between the sub-cloud layer and FT. For 2016, the FT dxs lower bound decreases substantially for $\mathrm{q}>1 \mathrm{~g} / \mathrm{kg}$ data and drastically for $\mathrm{q}>0.25 \mathrm{~g} / \mathrm{kg}$ data. However, at very low humidity, measurements are subject to higher uncertainties and should be treated with caution.

\subsection{Latitude-altitude curtains and vertical profiles}

Figures 7, 8, and 9 show latitude-altitude contour curtains of WISPER mean $q$, $q$-weighted mean $\delta \mathrm{D}$, and $q$ weighted mean $d x$ f for each of the three ORACLES sampling periods. Curtains were generated using Gaussian 
kernel density estimation with bandwidth estimated by Silverman's rule of thumb. For 2017 and 2018, most of the low altitude sections of the aircraft profiles captured decoupled MBLs. The inferred inversion tops (dot-dashed lines, see Fig. 8 caption) do not generally align with $q$ contours, which at first is unexpected. However, the BBAplumes overlying the MBLs had humidity values of 3 to $7 \mathrm{~g} / \mathrm{kg}$, and therefore water concentrations remained high even up to $4 \mathrm{~km}$ at times, erasing the normally strong humidity gradients at trade inversion tops.

\subsubsection{Joint information in $q$ and $\delta D$}

405 For ORACLES 2016, when the experiment domain was furthest south, there is visibly high spatial correlation between mean $q$ and $q$-weighted $\delta \mathrm{D}$ (Fig. 8a,b). In fact, a spatial correlation of 0.72 is obtained for altitudes below $4.5 \mathrm{~km}$ (computed from a gridded subsampling of points from the curtains; it was confirmed that subsampling resolution does not affect the result). Both curtains show strong vertical gradients near the MERRA mixed layer top, in line with the strong inversion topped MBLs observed during this sampling period. Above the MBL in the LT,

410 average $q$ and $\delta \mathrm{D}$ both drop but have higher values where there was BBA loaded air (inferred from the $180 \mathrm{ppbv}$ CO contour) and lower values elsewhere. It is clear that the LT moisture and $\delta \mathrm{D}$ both come from African PBL air. Meanwhile, the wedge of dry, isotopically depleted air between the MBL and the $180 \mathrm{ppbv}$ CO contour likely advected northward from higher latitudes due to anticyclonic flow. Both the dry air wedge and the LT colocation of moisture, isotopes, and $\mathrm{CO}$ are also seen in many of the individual vertical profiles, two of which are shown in Fig.

41510. MBL top is evident from sharp gradients in potential temperature, humidity, and $\delta \mathrm{D}$. Above the MBL, the moisture and $\delta \mathrm{D}$ correlate very clearly with $\mathrm{CO}$ concentration, showing BBA plumes at 3-3.5 km and cleaner, drier air beneath. These profiles also show that in some cases, the LT moisture coming from the African PBL can have $\delta \mathrm{D}$ almost as high as the MBL. As a final remark on Fig. 7, we note that within the MBL, $q$ and $\delta \mathrm{D}$ generally increase toward the equator, corresponding to increasing SSTs, although there are occasions when $\delta \mathrm{D}$ decreases with latitude.

420 The high spatial correlation between average $q$ and $q$-weighted $\delta \mathrm{D}$ in 2016 is not as visually clear in the other two sampling periods (figures 8 and 9). This is misleading for 2017, where a spatial correlation of 0.63 was found for altitudes below $4.5 \mathrm{~km}$. Upon closer inspection, a couple of LT features in the $2017 q$ and $\delta \mathrm{D}$ curtains do match (marked with thin blue line segments and filled circles on Fig. 8a,b). However, the $2018 q$ and $\delta \mathrm{D}$ are in fact less correlated, with a spatial correlation of only 0.26 below $4.5 \mathrm{~km}$. What is clear for both years is that the classic

425 feature of humidity contours deepening towards the equator do not show in $\delta \mathrm{D}$. Individual vertical profiles provide some insight. They suggest that $q$ and $\delta \mathrm{D}$ show clearer correlation in the well-mixed subcloud layer and the region just above, but that $\delta \mathrm{D}$ appears to correlate better with $\mathrm{CO}$ higher up in the LT. For the three profiles shown from 2017 (Fig. 11), CO concentrations show BBA plumes directly on top of the MBL. Within the well-mixed layer, both $q$ and $\delta \mathrm{D}$ are constant with height, and just above that both show step-down decreases. But higher up, $\delta \mathrm{D}$ remains

430 high even as $q$ decreases, attributed to the BBA plumes having high $\delta \mathrm{D}$. These features are also present in the two example profiles for 2018 (Fig. 12). $q$ and $\delta$ D both show gradients in the MBL of (a) and are both constant with height in the well-mixed layer of (b). However, above the blue shaded regions, the $\delta \mathrm{D}$ values clearly follow the $\mathrm{CO}$ concentration more so than $q$, even showing similar structures at vertical scales of $200 \mathrm{~m}$.

Revisiting Fig. 8 and 9, the idea that $q$ and $\delta \mathrm{D}$ show similar trends in the subcloud layers is supported. In Fig. 8, $q$ contours often run almost parallel to the subcloud layer top, and $\delta \mathrm{D}$ demonstrates stratification as well. However, in Fig. 9 the $q$ contours in the subcloud layer are more vertical, and $\delta \mathrm{D}$ is more uniform throughout the layer than it is for Fig. 8. Lastly, most of the profiles in figures 11 and 12 show a distinct $\delta \mathrm{D}$ feature that is present in the region directly above the subcloud layer, highlighted in blue. In these regions, $\delta \mathrm{D}$ decreases even though both the underlying MBL and overlying BBA plume have higher $\delta \mathrm{D}$ values. One idea is that this signal is due to a clean, dry air wedge as seen clearly in the 2016 curtain and profiles, but is more subtle in the 2017 and 2018 profiles. Alternatively, the highlighted regions could have experienced precipitation, which preferentially removes heavy isotopes. The data set captures these types of features with high fidelity enabling these hypotheses to be examined. 

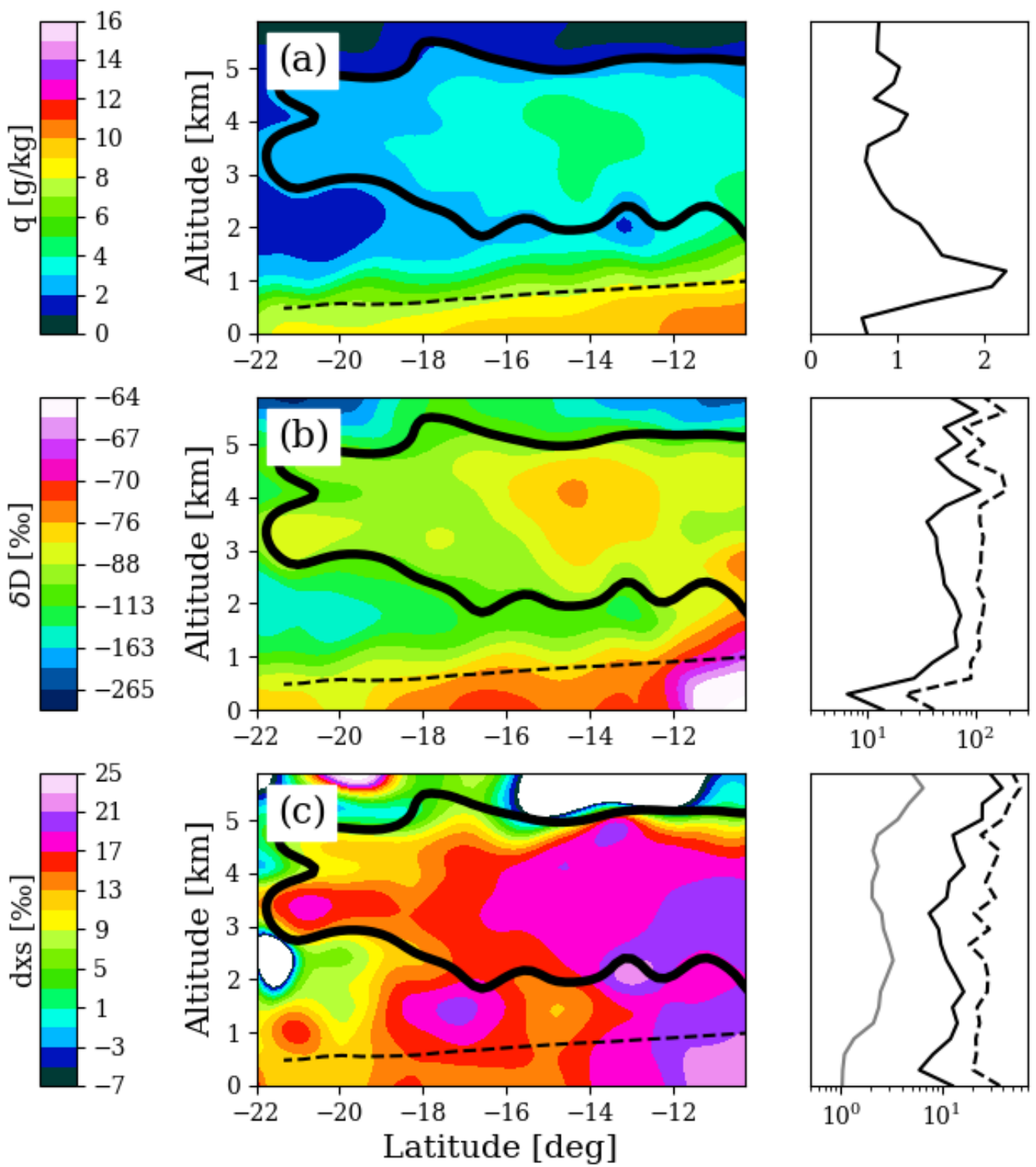

Figure 7: Latitude-altitude curtains of WISPER mean $q$ (a), $q$-weighted $\delta D(b)$, and $q$-weighted $d x s$ (c) for the ORACLES 2016 sampling period. Curtains were generated using a gaussian kernel estimation method after averaging the $1 \mathrm{~Hz}$ data into $10 \mathrm{~s}$ blocks and removing any data where $q<0.2 \mathrm{~g} / \mathrm{kg}$. Thick black contour shows $180 \mathrm{ppbv}$ in-situ carbon monoxide measured by the COMA system. Thin black dashed line shows mixed layer top taken from MERRA monthly mean output for Sept. 2016. Vertical profiles to the right of each curtain show typical and maximum standard deviation observed at each height (black solid and dashed respectively). For $d x s$, typical instrument precisions at each height are also shown (grey). 

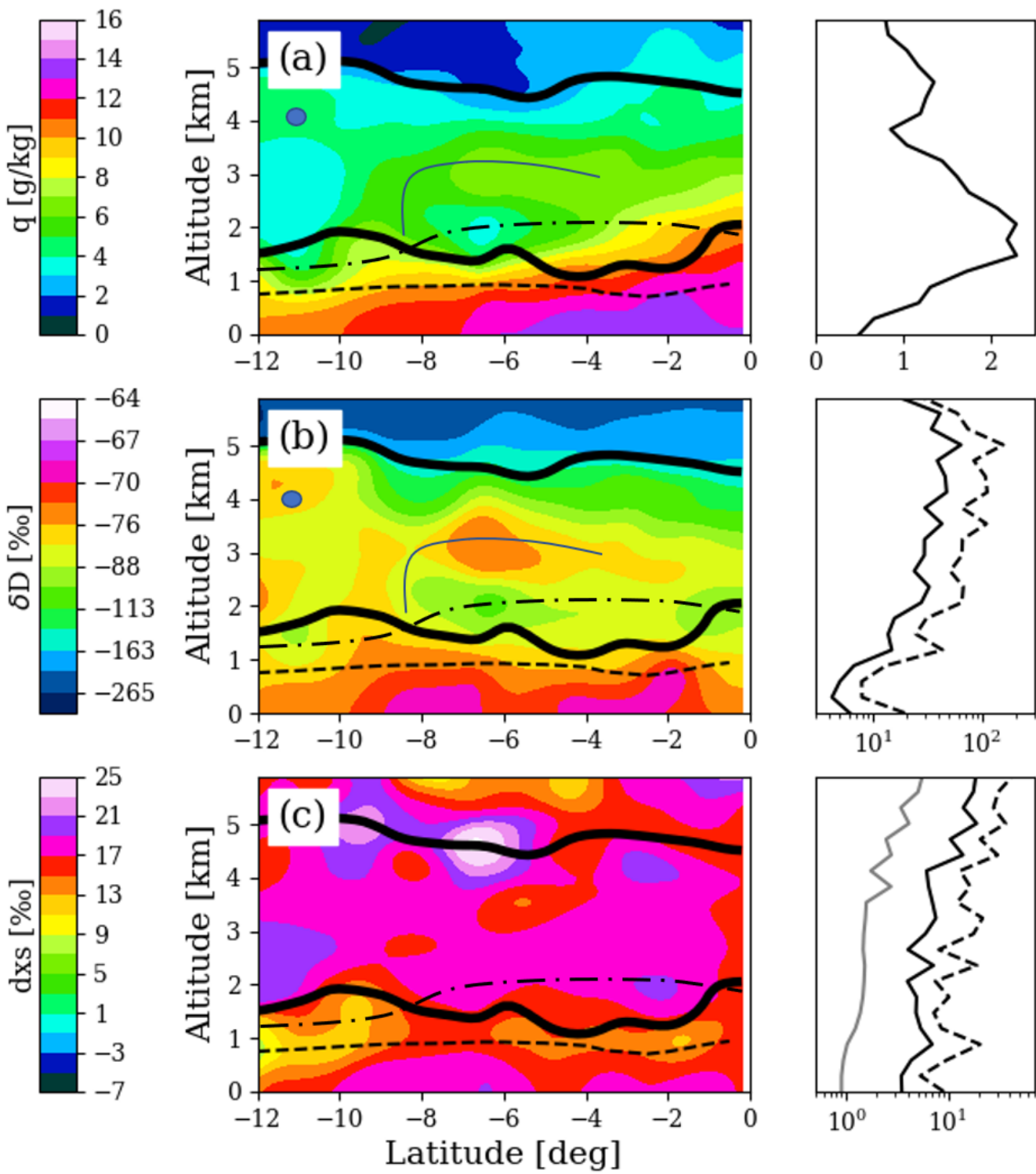

$10^{1}$

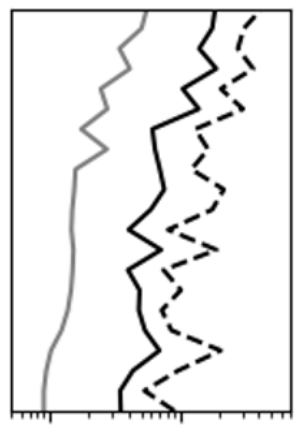

$10^{0} \quad 10^{1}$

Figure 8: Same as Fig. 7 but for the ORACLES 2017 sampling period. Thin dot-dashed contour is an estimation of trade inversion top. Trade inversion top was estimated roughly from in-situ cloud tops (in-situ liquid water content $>0.1 \mathrm{~g} / \mathrm{kg}$ ), when present, and otherwise where vertical derivative of temperature $\mathrm{dT} / \mathrm{dz}>0$. In cloudy conditions the two usually agreed to within $300 \mathrm{~m}$. The thin blue line segments and blue filled circles in (a) and (b) are visual aids showing features appearing in both $q$ and $\delta \mathrm{D}$. 

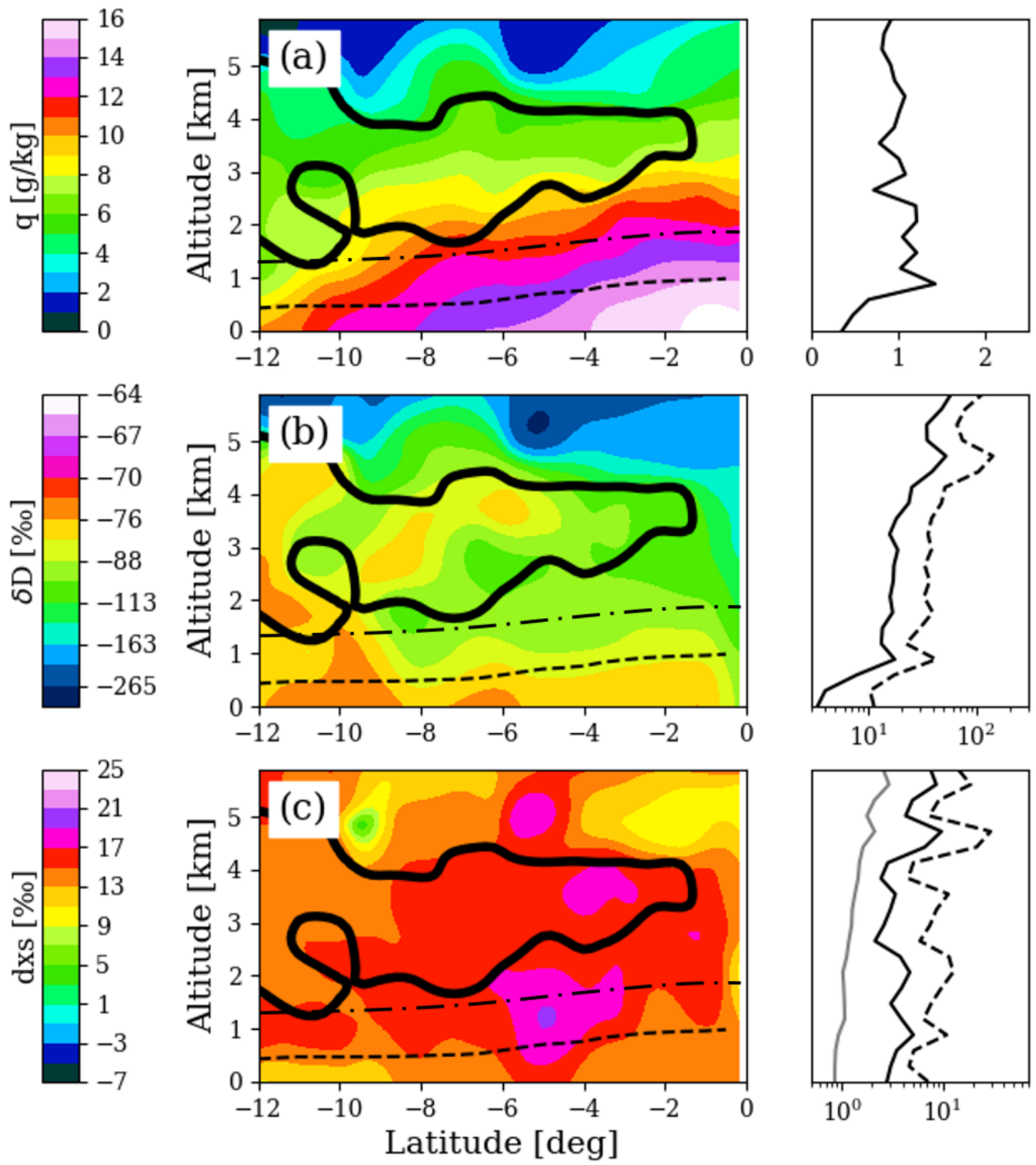

Figure 9: Same as Fig. 8 but for the ORACLES 2018 data. The method for determining trade inversion top did not yield clear results for latitudes north of $4^{\circ} \mathrm{S}$; trade inversion top at these latitudes should be treated as very rough estimates $(+/-$ 500m). 


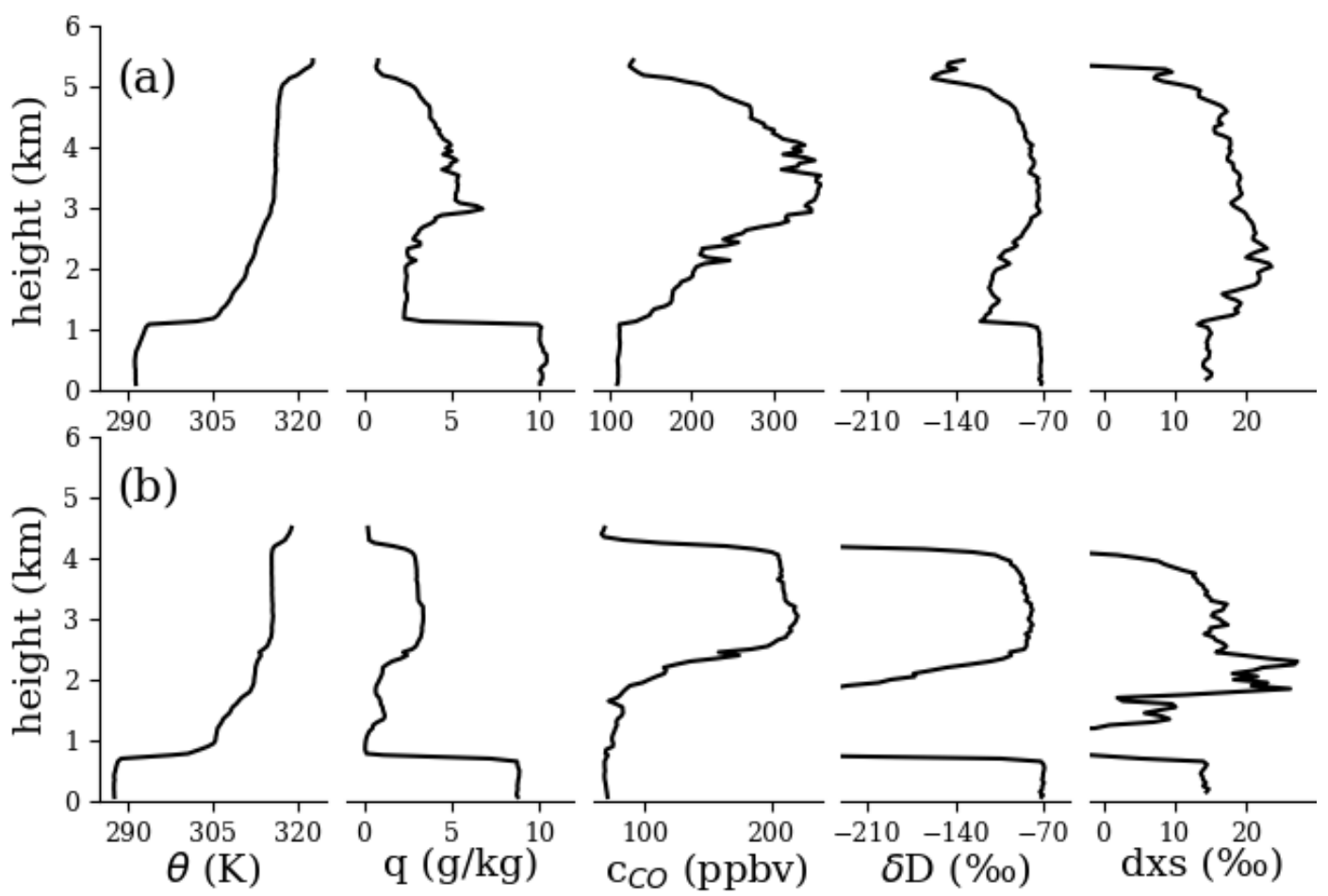

Figure 10: Vertical profiles of potential temperature, humidity, $\mathrm{CO}$ concentration, $\delta \mathrm{D}$, and $\mathrm{dxs}$ from vertical profiles taken on Aug. 31 (a) and Sept. 14 (b), 2016. Data were averaged into 50m vertical bins. The $d x s$ has an additional 3-bin running mean applied. The $\delta \mathrm{D}$ and $d x s$ in (b) become very low where $q$ approaches 0 and are not shown.

\subsubsection{Deuterium excess}

The $q$-weighted mean $d x s$ shows more spatial variability in 2016 than in the later two years. In the FT, this seems to follow the presence of BBA air, similarly to $\delta \mathrm{D}$. In the MBL, there is an increasing gradient toward the equator. This may be related to the southerly flow of the near surface air which brings cold, dry Southern Ocean air toward the equator and progressively warmer SSTs; in this case, the low relative humidity with respect to SST of cold dry air over warm SSTs would cause the ocean evaporation have high $d x s$.

For the 2017 and 2018 sampling periods, mean $d x s$ has low spatial correlation with both $q$ and $\delta \mathrm{D}$. Additionally, within the lower $4 \mathrm{~km} d x s$ does not typically vary by more than $4 \%$. This is most pronounced in 2018 , where mean dxs often varies by less than $2 \%$ for a fixed latitude. On the other hand, the vertical profiles of $d x s$ standard deviations show that higher variability does occur. Typical $d x s$ standard deviations (figures $8 \mathrm{c}$ and $9 \mathrm{c}$, solid black profiles) are $3 \%$ of which $30 \%$ cannot be distinguished from instrument precision (grey profiles). However, the maximum variabilities observed (black dashed profiles) show that in the most extreme cases $d x s$ can vary by 7-10 $\%$. Additionally, figures 11 and 12 show for instance, that $d x s$ can change by 5-10\%o between different vertical levels in a single profile, and $d x s$ appears to pick up vertical structure down to $\sim 250 \mathrm{~m}$. One particularly compelling case is found in Fig. $11 \mathrm{~b}$ where $d x s$ jumps from $13 \%$ near the surface to $4 \%$ in the decoupled layer, and then up to $20 \%$ in the overlying LT. It is not clear whether this variability simply reflects the advection of different air sources with different RH conditions or is the result of non-equilibrium processes occurring in the atmosphere postevaporation. However, given a single profile signal to noise ratio of 3 or 4 to 1 as evident in the figure, relevant quantitative (model-based) tests can be developed. 

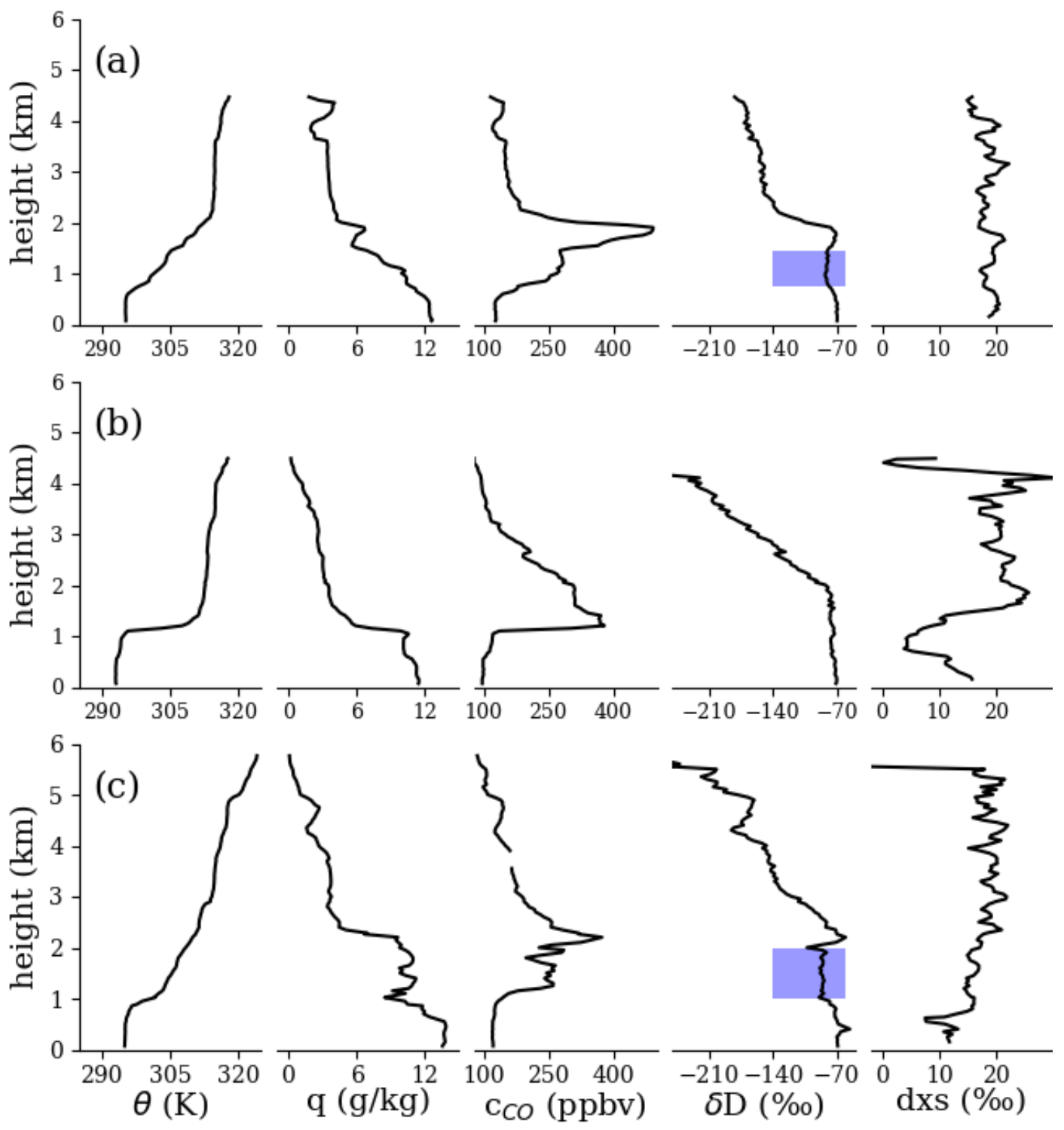

Figure 11: Vertical profiles of potential temperature, humidity, $C O$ concentration, $\delta D$, and dxs from two vertical profiles taken on Aug. 15, 2017 (a, b) and one on Aug. 26, 2017 (c). Data were averaged into 50m vertical bins. The $d x s$ has an additional 3-bin running mean applied. Blue highlighted regions are discussed in the main text. 

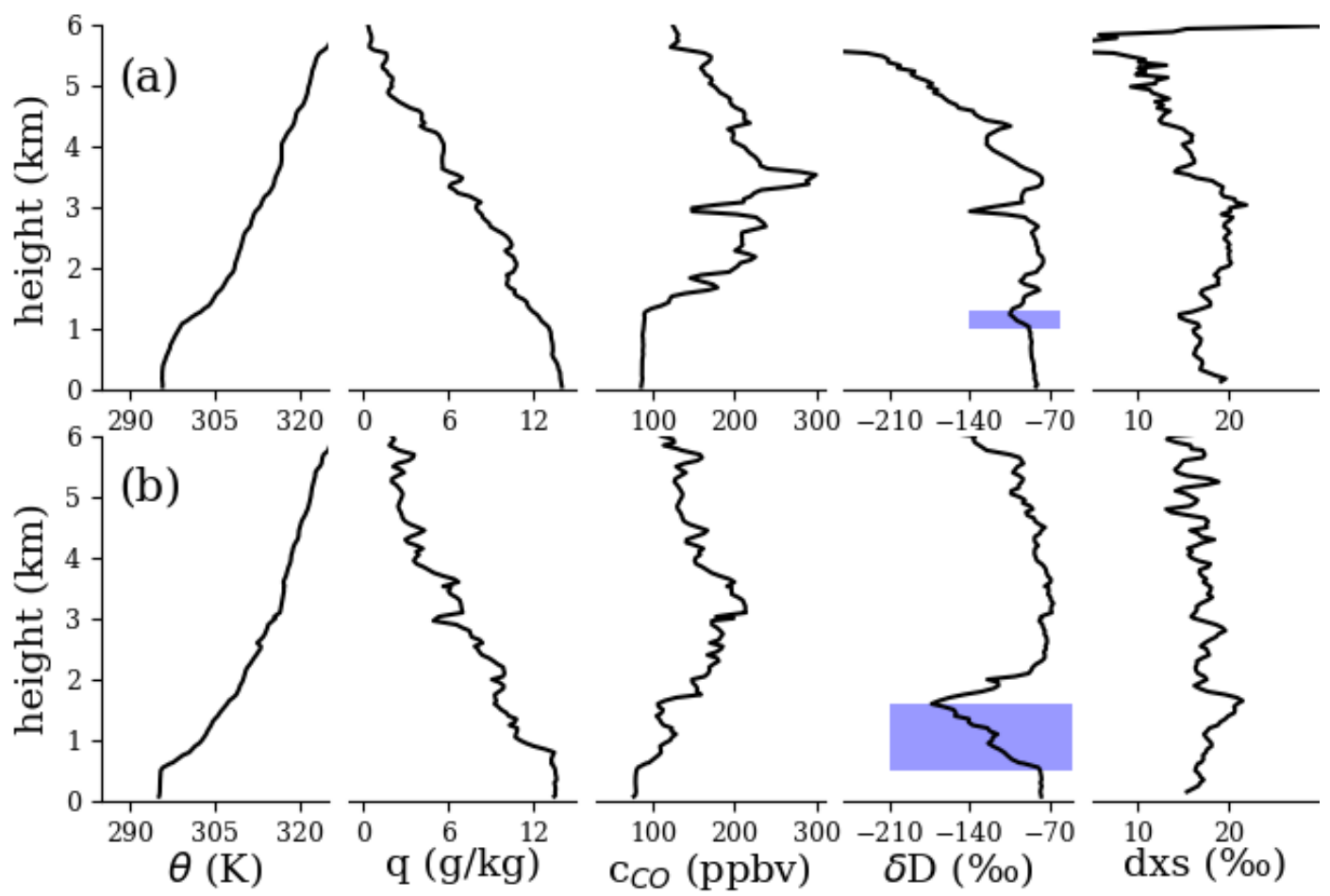

Figure 12: Vertical profiles of potential temperature, humidity, $C O$ concentration, $\delta D$, and dxs from vertical profiles taken on Oct. 03 (a) and Oct. 19 (b), 2018. Data were averaged into 50m vertical bins. Blue highlighted regions are discussed in the main text.

\section{Final remarks}

In-situ measurements of humidity and water vapor heavy isotope ratios were made alongside a wide range of other meteorological, trace gas, and aerosol variables aboard the P3 Orion aircraft during the NASA ORACLES project. The project entailed measurements in the southeast Atlantic marine boundary layer and lower troposphere over latitudes $22^{\circ} \mathrm{S}$ to the equator, and over the months of Sept. 2016, Aug. 2017, and Oct. 2018. Thirty-nine non-transit flights were evenly spread over the three months and collected over 300 hours of $1 \mathrm{~Hz}$ data. Due to ample data at all levels in the LT spanning $70 \mathrm{~m}$ to $6 \mathrm{~km}$, this dataset provides valuable information on the vertical structure of isotopic compositions in the region.

In this paper, an overview of WISPER, the system used to measure isotope ratios, has been provided, along with details of the calibration methods, uncertainty estimates, and suggested data usage. Some of the features of the isotope ratio dataset were highlighted in latitude-altitude curtains and vertical profiles, focusing on $\delta \mathrm{D}$ and $d x s$. To the authors' knowledge, these curtains are the most comprehensive compilation of lower tropospheric in-situ profile measurements presently available. Individual profiles show that within the subcloud well-mixed layer, $\delta \mathrm{D}$ vertical structure tends to mirror q, as both are likely tied to near surface and mixing processes. On the other hand, $\delta \mathrm{D}$ above the MBL is often more closely correlated with CO than $q$. This indicates that LT $\delta \mathrm{D}$ is tracing moisture coming from the African PBL. In the vertical profiles shown for 2017 and 2018, there are several instances of regions just above the well-mixed layer with depleted $\delta \mathrm{D}$ values even though air above and below have higher $\delta \mathrm{D}$. One possibility is precipitation preferentially removing the heavy isotopes, although further research is needed. 
For $d x s$ measurements, the $q$-weighted mean characteristics show low spatial variability, but variations of $5 \%$ or more and vertical features down to $\sim 250 \mathrm{~m}$ resolution are present in individual profiles. The fact that vertical structure in the $d x s$ as well as the $\delta \mathrm{D}$ are clearly captured encourages their use to constrain vertically resolved models that include isotopes. There are now idealized, large eddy simulation, and GCM models which include isotopes (e.g., Galewsky et al., 2016 and references therein) and the contribution of convection and cloud microphysics to the vertical structure of isotopic content can be compared to vertical profiles from the ORACLES WISPER measurements. Further, traditional thermodynamic analyses such as $q$ vs. $\theta_{\mathrm{e}}$ mixing diagrams (e.g. Betts and Albrecht, 1987) to diagnose the vertical structure of MBLs could be supplemented by similar isotope ratio thermodynamic charts. Utilizing the ORACLES WISPER dataset with these types of analytical approaches can refine our conceptual understanding of MBL energy and moisture budgets. Further, comprehensive modeling which includes both isotopes and other variables such as temperature could provide stronger quantitative constraints on these budgets.

\section{Appendix A: The WISPER CVI}

The CVI inlet used in this study was adapted from the NSF Gulfstream-V inlet (G-V CVI) deployed frequently over the past several decades. All of the hardware mounted to the aircraft fuselage was identical to the G-V CVI, with some important changes to the heaters to reduce the possibility of cold spots occurring along the sample line where water might condense and reevaporate. This is critical for accurate measurements of isotopologues of water. A new rack-mounted heater and flow control electronics unit was designed and built with contemporary components, in part because many components used in the two-decade-old G-V CVI electronics unit are obsolete, but also to improve several aspects of the counterflow operation critical for mitigating issues that might impact isotope ratio

540 measurements. In particular, the relatively slow Omega multi-channel heater controller used on the G-V CVI was replaced with four separate, fast heater controllers (Minco CT-325) for more stable temperature control. Whereas the platinum RTD temperature sensor used for sensing temperature on the $\sim 50-\mathrm{cm}$ long, $2.5 \mathrm{~cm}$ O.D. stainless steel sample line that extends from probe tip to the mounting plate of the inlet on the G-V is located at the extreme downstream end of the sample line (i.e., at the mounting plate), the Pt-RTD was placed approximately $15-\mathrm{cm}$

545 downstream of the junction with the probe tip to provide more uniform heating in the critical droplet-evaporation region. Finally, a new, independent heating zone was added to the P-3 pylon necessary to extend the probe tip beyond the aircraft boundary layer, whereas the G-V CVI system uses a single heating zone for the transfer line when the inlet is attached to a pylon (e.g., when mounted to the NCAR C-130 aircraft).

New, fast-response flow controllers were used for more precise control of counterflow. In addition, rather than using

550 a flow controller for each individual instrument sampling from the CVI, as is currently the arrangement on the G-V CVI, two mass flow controllers (MFCs) were used to maintain a more stable sample flow. One (Alicat model MCseries, adjusted to use a wider orifice to enable a lower pressure drop at higher altitude) served to maintain a mass flow ranging from 2-5 STP liters per minute (SLM) as a bypass to the first isotopic analyzer (Fig. 3). The second was a high-flow MFC (Alicat model MCW, 20 SLPM) placed after the CVI transfer line split-off to the other

555 instruments using the CVI. This MFC provided larger flow of 5-9 STP SLPM necessary to reduce the enhancement factor in clouds with high cloud-water contents and reduce the risk of condensation of water in the sample lines. The flow through the high-flow MFC was also used as a source for other instruments measuring from the CVI inlet (as described elsewhere).

New $\mathrm{C}++$ software was also developed for more precise control of the feedback loop necessary to maintain an

560 excess counterflow and limit infiltration of ambient air. This feedback loop operated at $10 \mathrm{~Hz}$, as opposed to $1 \mathrm{~Hz}$ on the G-V CVI, reducing the impact of oscillations that allow "leakage" of ambient air into the inlet during periods of strong turbulence.

\section{Appendix B: Gulper absolute calibration offset for 2016}

565 The absolute $\delta$ calibration for Gulper is assumed to be linear. Therefore, for a measurement in the field by Gulper $\delta_{\mathrm{G}}$ :

$$
\mathrm{m}_{\mathrm{G}} \delta_{\mathrm{G}}+b_{G}=\delta_{\text {true }} \text {, }
$$$$
\rightarrow b_{G}=\delta_{\text {true }}-\mathrm{m}_{\mathrm{G}} \delta_{\mathrm{G}} \text {, }
$$ 
where $m_{G}, b_{G}$ are the calibration slope and offset, $\delta_{\text {true }}$ is the true value. The slope, $m_{G}$, is known from calibrations but an estimate of the intercept $b_{G}$ must be obtained. Due to field constrains on calibration, a direct determination using (A1) that utilized an absolute reference $\left(\delta_{\text {true }}\right)$ was not possible. $\delta_{\text {true }}$ is therefore estimated from calibrated Mako measurements by assuming that for a histogram of sub-cloud layer values during similar P3 flight tracks and synoptic conditions, the histogram peak should be roughly the same. By taking $\delta_{\mathrm{G}}$ as the peak for Gulper flights and $\delta_{\text {true }}$ as the peak of Mako flights, (A1) is used to estimate $b_{G}$. The 2016 P3 routine flights (same flight tracks) for Mako were Aug. 31 and Sept. 04. The routine flights for Gulper were Sept. 10, 12, and 25.

\section{Data availability}

The WISPER data along with other ORACLES P3 variables for the Sept. 2016, Aug. 2017, and Oct. 2018 sampling periods are publicly accessible at https://doi.org/10.5067/Suborbital/ORACLES/P3/2016_V2,

580 https://doi.org/10.5067/Suborbital/ORACLES/P3/2017 V2, and https://doi.org/10.5067/Suborbital/ORACLES/P3/2018_V2, respectively (see references for ORACLES Science Team, 2020 - 2016 P3 data, 2017 P3 data, and 2018 P3 data). For the current DOIs (V2), the WISPER data contained in the $1 \mathrm{~Hz}$ merge files should be used (listed as "ORACLES Merged Datasets" in the archive). The merge files collect most of the P3 variables into single .nc files (one file per flight). Only research flights RF 01-13 from each sampling period should be used for most analyses (see Table 1). Data for transit flights to and from the study regions have been minimally processed and for most users should be ignored. Table 7 describes all WISPER variables.

Table 7: WISPER variables. More information on 'Pic1' vs 'Pic2' can be found in the first paragraph of Section 3 and in Section 5.1. Variables ending in '_tot1' and 'cld' are only available for the Aug. 2017 and Oct. 2018 sampling periods.

\begin{tabular}{|c|c|c|}
\hline Variable name & Units & Description \\
\hline wisper_valve_state & $0 / 1$ & 1 if Picl is on CVI, 0 if Picl is on SDI. \\
\hline h2o_tot1 & ppmv & Total water mixing ratio measured with Picl. \\
\hline h2o_tot 2 & ppmv & Total water mixing ratio measured with Pic2. \\
\hline h2o_cld & ppmv & Cloud water mixing ratio (including ice). \\
\hline dD_tot1 & $\%$ & Total water $\mathrm{D} / \mathrm{H}$ ratio (delta-notation) measured with Pic1. \\
\hline std_dD_tot 1 & $\%$ & $1 \mathrm{~Hz}$ precision in $\mathrm{dD}$ _tot 1. \\
\hline dD_tot2 & $\%$ & Total water $\mathrm{D} / \mathrm{H}$ ratio (delta-notation) measured with Pic2. \\
\hline std_dD_tot2 & $\%$ & $1 \mathrm{~Hz}$ precision in $\mathrm{dD}$ _tot 2. \\
\hline dD_cld & $\%$ & Cloud water $\mathrm{D} / \mathrm{H}$ ratio (delta-notation). \\
\hline std_dD_cld & $\%$ & $1 \mathrm{~Hz}$ precision in dD_cld. \\
\hline d180_tot1 & $\%$ & Total water $\mathrm{O}^{18} / \mathrm{O}^{16}$ ratio (delta-notation) measured with Pic 1 . \\
\hline std_d180_tot 1 & $\%$ & $1 \mathrm{~Hz}$ precision in $\mathrm{d} 18 \mathrm{O} \_$tot 1. \\
\hline d180_tot2 & $\%$ & Total water $\mathrm{O}^{18} / \mathrm{O}^{16}$ ratio (delta-notation) measured with Pic2. \\
\hline std_d180_tot2 & $\%$ & $1 \mathrm{~Hz}$ precision in $\mathrm{d} 18 \mathrm{O} \_$tot 2 . \\
\hline d180_cld & $\%$ & Cloud water $\mathrm{O}^{18} / \mathrm{O}^{16}$ ratio (delta-notation) measured with Pic 1 \\
\hline std_d180_cld & $\%$ & $1 \mathrm{~Hz}$ precision in $\mathrm{d} 18 \mathrm{O}$ _cld. \\
\hline cvi lwe & $\mathrm{g} / \mathrm{kg}$ & Cloud liquid+ice water content, derived from 'h2o_cld'. \\
\hline cvi_enhance & none & Enhancement factor for the CVI inlet. \\
\hline cvi_dcut50 & $\mu \mathrm{m}$ & Cutoff diameter for CVI inlet. \\
\hline cvi_inFlow & SLPM & Intake flow of CVI inlet. \\
\hline cvi_xsFlow & SLPM & Excess dry air counterflow for CVI inlet. \\
\hline cvi_userFlow & SLPM & Sum of CVI flow rates for all other instruments. \\
\hline
\end{tabular}




\section{Author contributions}

DH, DN and DT developed the CVI and WISPER hardware and control software. DN and DH undertook the field deployments with remote support by DT. DH wrote the post-processing and quality control code, selection of the calibration model, and led drafting of the manuscript to which all authors contributed.

\section{Acknowledgments}

This work was supported by a grant from the National Science Foundation Climate and Large-scale Dynamics and Atmospheric Chemistry programs (NSF grant 1564670). ORACLES was a NASA Earth Venture Suborbital-2 investigation managed through the Earth System Science Pathfinder Office. We wish to thank Drs. Jen Redemann, Robert Wood, and Paquita Zuidema for facilitating integration of the isotopic measurements within the ORACLES plan and for coordination with the NSF sponsored activities. Dr. Bryan Rainwater assisted in the development and initial testing of some of the hardware and software components. We acknowledge Dr. Jorgen Jensen of the National Center for Atmospheric Research Aviation Facility for providing guidance and critical scientific and technical

605 assistance in manufacturing the counter-flow virtual impactor hardware. We similarly are indebted to the staff and flight crew at the NASA Airborne Science Program based at the Wallops Flight Facility, for assistance with engineering and logistics support for the measurement program. DN and DH wish to thank experiment coinvestigators with whom we spent hundreds of hours flying over the South Atlantic with good humor.

\section{Competing interests}

The authors declare that they have no conflict of interest.

\section{References}

Adebiyi, A., and Zuidema, P.: The Role of the Southern African Easterly Jet in Modifying the Southeast Atlantic Aerosol and Cloud Environments, Quarterly Journal of the Royal Meteorological Society, 142, 697, 1574-89. https://doi.org/10.1002/qj.2765, 2016.

Bailey, A., Noone, D., Berkelhammer, M., Steen-Larsen, H. C., and Sato, P.: The stability and calibration of water vapor isotope ratio measurements during long-term deployments, Atmos. Meas. Tech., 8, 4521-4538, https://doi.org/10.5194/amt-8-4521-2015, 2015.

Benetti, M., Steen-Larsen, H., Reverfdin, G., Sveinbjörnsdottir, A., Aloisi, G., Berkelhammer, M., Bourlès, B., Bourras, D., de coetlogon, G., Cosgrove, A., Faber, A.-K., Grelet, J., Hansen, S., \& Johnson, R., Legoff, H., Martin, N., Peters, A., Popp, T., Reynaud, T., Winther, M.: Stable isotopes in the atmospheric marine boundary layer water vapour over the Atlantic Ocean, 2012-2015,. Sci. Data 4, 160128, https://doi.org/10.1038/sdata.2016.128, 2017.

Betts, A. K., and Albrecht, B. A.: Conserved Variable Analysis of the Convective Boundary Layer Thermodynamic Structure over the Tropical Oceans, Journal of Atmospheric Sciences, 44(1), 83-99, 1987.

Bony, S., and Dufresne, J. L.: Marine boundary layer clouds at the heart of tropical cloud feedback uncertainties in climate models, Geophysical Research Letters, 32, L20806. https://doi.org/10.1029/2005GL023851, 2005.

Boucher, O., Randall, D., Artaxo, P., Bretherton, C., Feingold, G., Forster, P., Kerminen, V.-M., Kondo, Y., Liao, H., Lohmann, U., Rasch, P., Satheesh, S.K., Sherwood, S., Stevens, B., and Zhang, X.Y.: Clouds and Aerosols. In: Climate Change 2013: The Physical Science Basis. Contribution of Working Group I to the Fifth Assessment Report of the Intergovernmental Panel on Climate Change [Stocker, T.F., D. Qin, G.-K. Plattner, M. Tignor, S.K. Allen, J. Boschung, A. Nauels, Y. Xia, V. Bex and P.M. Midgley (eds.)], Cambridge University Press, Cambridge, United Kingdom and New York, NY, USA, 2013.

Coplen, T. B.: Reporting of stable hydrogen, carbon, and oxygen isotopic abundances, Pure Appl. Chem., 66, 273276, 1994.

Dyroff, C., S. Sanati, E. Christner, A. Zahn, M. Balzer, H. Bouquet, J. B. McManus, Y. Gonzalez-Ramos, and M. Schneider: Airborne in situ vertical profiling of $\mathrm{HDO} / \mathrm{H}_{2}{ }^{16} \mathrm{O}$ in the subtropical troposphere during the musica 
remote sensing validation campaign, Atmos. Meas. Tech., 8(5), 2037-2049, doi:10.5194/amt-8-2037-2015, 2015.

Ehhalt, D. H.: Vertical Profiles of HTO, HDO, and H2O in the Troposphere (No. NCAR/TN-100+STR), University Corporation for Atmospheric Research, doi:10.5065/D6BP00QB, 1974.

Galewsky, J., Steen-Larsen, H. C., Field, R. D., Worden, J., Risi, C., and Schneider, M.: Stable isotopes in atmospheric water vapor and applications to the hydrologic cycle, Rev. Geophys., 54, 809-865, doi:10.1002/2015RG000512, 2016

Garstang, M., Tyson, P. D., Swap, R., Edwards, M., Kållberg, P., and Lindesay, J. A.: Horizontal and vertical transport of air over southern Africa, J. Geophys. Res., 101( D19), 23721-23736, doi:10.1029/95JD00844, 1996.

Gat, J. R., Klein, B., Kushnir, Y., Roether, W., Wernli, H., Yam, R., and Shemesh, A.: Isotope composition of air moisture over the Mediterranean Sea: an index of the air-sea interaction pattern, Tellus B, 55, 953-965, 2003.

Herman, R. L., Cherry, J. E., Young, J., Welker, J. M., Noone, D., Kulawik, S. S., and Worden, J.: Aircraft validation of Aura Tropospheric Emission Spectrometer retrievals of HDO/H2O, Atmos. Meas. Tech., 7(9), 3127-3138, 2014.

Howell, S. G., Freitag, S., Dobracki, A., Smirnow, N., and Sedlacek III, A. J.: Undersizing of Aged African Biomass Burning Aerosol by an Ultra High Sensitivity Aerosol Spectrometer, Atmos. Meas. Tech. Discuss. [preprint], https://doi.org/10.5194/amt-2020-416, in review, 2020.

Liu, X., Huey, L. G., Yokelson, R. J., Selimovic, V., Simpson, I. J., Müller, M., Jimenez, J. L., Campuzano-Jost, P., Beyersdorf, A. J., Blake, D. R., Butterfield, Z., Choi, Y., Crounse, J. D., Day, D. A., Diskin, G. S., Dubey, M. K., Fortner, E., Hanisco, T. F., Hu, W., King, L. E., Kleinman, L., Meinardi, S., Mikoviny, T., Onasch, T. B., Palm, B. B., Peischl, J., Pollack, I. B., Ryerson, T. B., Sachse, G. W., Sedlacek, A. J., Shilling, J. E., Springston, S., St. Clair, J. M., Tanner, D. J., Teng, A. P., Wennberg, P. O., Wisthaler, A., and Wolfe, G. M.: Airborne measurements of western U.S. wildfire emissions: Comparison with prescribed burning and air quality implications, J. Geophys. Res.-Atmos., 122, 6108-6129, https://doi.org/10.1002/2016jd026315, 2017.

McNaughton, C. S., Clarke, A. D., Howell, S. G., Pinkerton, M., Anderson, B., Thornhill, L., Winstead, E., Hudgins, C., Dibb, J. E., Scheuer,E., and Maring, H.: Results from the DC-8 inlet characterization experiment (DICE): Airborne versus surface sampling of mineral dust and sea salt aerosols, Aerosol Sci. Tech., 41, 136159, https://doi.org/10.1080/02786820601118406, 2007.

Noone, D., Risi, C., Bailey, A., Berkelhammer, M., Brown, D. P., Buenning, N., Gregory, S., Nusbaumer, J., Schneider, D., Sykes, J., Vanderwende, B., Wong, J., Meillier, Y., and Wolfe, D.: Determining water sources in the boundary layer from tall tower profiles of water vapor and surface water isotope ratios after a snowstorm in Colorado, Atmos. Chem. Phys., 13, 1607-1623, https://doi.org/10.5194/acp-13-1607-2013, 2013.

Noone, K. J., Ogren, J. A., Heintzenberg, J., Charlson, R. J., and Covert, D. S.: Design and calibration of a counterflow virtual impactor for sampling of atmospheric fog and cloud droplets, Aerosol Sci. Tech., 8:3, 235 244, DOI:10.1080/02786828808959186, 1988.

ORACLES Science Team: Suite of Aerosol, Cloud, and Related Data Acquired Aboard P3 During ORACLES 2016, Version 2, NASA Ames Earth Science Project Office, doi: 10.5067/Suborbital/ORACLES/P3/2016_V2, 2020.

ORACLES Science Team: Suite of Aerosol, Cloud, and Related Data Acquired Aboard P3 During ORACLES 2017, Version 2, NASA Ames Earth Science Project Office, doi: 10.5067/Suborbital/ORACLES/P3/2017_V2, 2020.

ORACLES Science Team: Suite of Aerosol, Cloud, and Related Data Acquired Aboard P3 During ORACLES 2018, Version 2, NASA Ames Earth Science Project Office, doi: 10.5067/Suborbital/ORACLES/P3/2018_V2, 2020.

Pfahl, S. and Sodemann, H.: What controls deuterium excess in global precipitation?, Clim. Past, 10, 771-781, https://doi.org/10.5194/cp-10-771-2014, 2014

Redemann, J., Wood, R., Zuidema, P., Doherty, S. J., Luna, B., LeBlanc, S. E., Diamond, M. S., Shinozuka, Y., Chang, I. Y., Ueyama, R., Pfister, L., Ryoo, J.-M., Dobracki, A. N., da Silva, A. M., Longo, K. M., Kacenelenbogen, M. S., Flynn, C. J., Pistone, K., Knox, N. M., Piketh, S. J., Haywood, J. M., Formenti, P., Mallet, M., Stier, P., Ackerman, A. S., Bauer, S. E., Fridlind, A. M., Carmichael, G. R., Saide, P. E., Ferrada, G. 
A., Howell, S. G., Freitag, S., Cairns, B., Holben, B. N., Knobelspiesse, K. D., Tanelli, S., L'Ecuyer, T. S., Dzambo, A. M., Sy, O. O., McFarquhar, G. M., Poellot, M. R., Gupta, S., O'Brien, J. R., Nenes, A., Kacarab, M., Wong, J. P. S., Small-Griswold, J. D., Thornhill, K. L., Noone, D., Podolske, J. R., Schmidt, K. S., Pilewskie, P., Chen, H., Cochrane, S. P., Sedlacek, A. J., Lang, T. J., Stith, E., Segal-Rozenhaimer, M., Ferrare, R. A., Burton, S. P., Hostetler, C. A., Diner, D. J., Seidel, F. C., Platnick, S. E., Myers, J. S., Meyer, K. G., Spangenberg, D. A., Maring, H., and Gao, L.: An overview of the ORACLES (ObseRvations of Aerosols above CLouds and their intEractionS) project: aerosol-cloud-radiation interactions in the southeast Atlantic basin, Atmos. Chem. Phys., 21, 1507-1563, https://doi.org/10.5194/acp-21-1507-2021, 2021.

Risi, C., Bony, S., and Vimeux, F.: Influence of convective processes on the isotopic composition (d18O and dD) of precipitation and atmospheric water in the tropics. Part 2: Physical interpretation of the amount effect, J. Geophys. Res., 113, D19306, doi:10.1029/2008JD009943, 2008.

Rosenberg, P. D., Dean, A. R., Williams, P. I., Dorsey, J. R., Minikin, A., Pickering, M. A., and Petzold, A.: Particle sizing calibration with refractive index correction for light scattering optical particle counters and impacts upon PCASP and CDP data collected during the Fennec campaign, Atmos. Meas. Tech., 5, 1147-1163, https://doi.org/10.5194/amt-5-1147-2012, 2012.

Schmidt, M., Maseyk, K., Lett, C., Biron, P., Richard, P., Bariac, T., and Seibt, U.: Concentration effects on laserbased $\delta 18 \mathrm{O}$ and $\delta 2 \mathrm{H}$ measurements and implications for the calibration of vapour measurements with liquid standards, Rapid Commun. Mass Spectrom., 24, 3,553-3,561, 2010.

Seabold, S., \& Perktold, J.: statsmodels: Econometric and statistical modeling with python, 9th Python in Science Conference, 2010.

Tremoy, G., Vimeux, F., Cattani, O., Mayaki, S., Souley, I., and Favreau, G.: Measurements of water vapor isotope ratios with wavelength scanned cavity ring-down spectroscopy technology: New insights and important caveats for deuterium excess measurements in tropical areas in comparison with isotope-ratio mass spectrometry, Rapid Commun. Mass Spectrom., 25, 3469-3480, 2011.

Twohy, C., Schanot, A., and Cooper, W. A.: Measurement of condensed water content in liquid and ice clouds using an airborne counterflow virtual impactor, J. Atmos. Oceanic Technol., 14, 197-202, 1997.

Uemura, R., Matsui, Y., Yoshimura, K., Motoyama, H., and Yoshida, N.: Evidence of deuterium excess in water vapor as an indicator of ocean surface conditions, J. Geophys. Res., 113, D19114, doi:10.1029/2008JD010209, 2008.

Vial, J., Bony, S., Stevens, B., and Vogel, R.: Mechanisms and Model Diversity of Trade-Wind Shallow Cumulus Cloud Feedbacks: A Review, Surv. Geophys., 38, 1331-1353. https://doi.org/10.1007/s10712-017-9418-2, 2017.

Virtanen, P., Gommers, R., Oliphant, T. E., Haberland, M., Reddy, T., Cournapeau, D., Burovski, E., Peterson, P., Weckesser, W., Bright, J., van der Walt, S. J., Brett, M., Wilson, J., Jarrod Millman, K., Mayorov, N., Nelson, A. R. J., Jones, E., Kern, R., Larson, E., Carey, CJ., Polat, İ., Feng, Y., Moore, E. W., VanderPlas, J., Laxalde, D., Perktold, J., Cimrman, R., Henriksen, I., Quintero, E.A., Harris, C. R., Archibald, A. M., Ribeiro, A. H., Pedregosa, F., van Mulbregt, P., and SciPy 1.0 Contributors.: SciPy 1.0: Fundamental Algorithms for Scientific Computing in Python. Nature Methods, 17(3), 261-272, 2020.

Wood, R.: Stratocumulus Clouds, Mon. Wea. Rev., 140, 2373-2423, https://doi.org/10.1175/MWR-D-11-00121.1, 2012. 